Article

\title{
Spatio-Temporal Visualisation of Reflections from Building Integrated Photovoltaics
}

\author{
Roland Schregle $^{1, *(\mathbb{D})}$, Christian Renken $^{2}$ and Stephen Wittkopf ${ }^{1}$ (i) \\ 1 School of Engineering and Architecture, Lucerne University of Applied Sciences and Arts, \\ Technikumstrasse 21, CH-6048 Horw, Switzerland; stephen.wittkopf@hslu.ch \\ 2 CR Energie GmbH, Z.I. l'Epine 7, CH-1868 Collombey, Switzerland; christian.renken@crenergie.ch \\ * Correspondence: roland.schregle@hslu.ch; Tel.: +41-41-349-3626
}

Received: 18 May 2018; Accepted: 31 July 2018; Published: 3 August 2018

\begin{abstract}
With the increasing adoption of building integrated photovoltaics (BIPV), concerns arise about potential glare. While recommended criteria to assess glare exist, it is challenging to apply these in the spatial and temporal domains and communicate the complex data to planning authorities and clients. This paper presents a new computational workflow using annual daylight simulation, material modelling using bi-directional scattering distribution functions (BSDFs) and image-based postprocessing to obtain 3-dimensional renderings of cumulative annual irradiance and glare duration on the built environment. The annual daylight simulation considers relevant sun positions in high temporal resolution (15-min timesteps) and measured BSDFs to model different PV materials. The postprocessing includes a relative irradiance visualisation comparing the impact of a proposed $\mathrm{PV}$ proportional to a reference material. It also includes a new spatio-temporal workflow to assess the glare duration based on recommended thresholds. This workflow is demonstrated with a case study of a proposed PV roof for a church, assessing the glare potential of two different PV materials. The visualisations indicate glare durations well below the thresholds with satinated PVs, and in noncritical zones outside observer positions with standard PVs. Thus the proposed PV roof does not cause any disturbing glare.
\end{abstract}

Keywords: building integrated photovoltaics; annual daylight simulation; reflection; RADIANCE; photon mapping; BSDF; HDR; image processing; feature detection

\section{Introduction}

The integration of photovoltaics (PV) into building façades as building integrated photovoltaics (BIPV) holds opportunities in meeting the increasing demand for renewable energy. BIPV significantly improves the energy balance of buildings and their autonomy. The dramatic cost reduction in recent years along with a diversity in available designs have motivated the increasing use of BIPV. The appearance of BIPV corresponds to that of glass façades, as PV modules are typically laminated with glass. This has in turn influenced the development of urban architecture, with a shift from traditional construction materials such as plaster or fibre cement towards an increasing prevalence of glass façades in general, and BIPV in particular.

A negative side effect of this development are potentially disturbing reflections from specular façades, which pose a challenge for building and environmental authorities [1]. Specular reflections are problematic because they may give rise to glare, which impacts occupants in adjacent buildings as well as pedestrians, but also personnel in critical environments such as airports [2]. A high luminance in the observer's field of view, particularly in contrast to indoor luminance, can result in discomfort glare as the eye strains to accommodate the contrast, leading to rapid fatigue. In severe cases where the luminance is high enough to cause temporary visual impairment and after-images on the retina, 
this results in disability glare. Glare is highly subjective, and there is considerable variation in tolerance among individuals. As such, glare is typically expressed as a probability index rather than fixed metric thresholds [3].

Consequently there is a demand for criteria to objectively assess the impact of specular reflections in architecture, and take countermeasures if necessary. As these countermeasures can be costly, legislation is required to prevent such situations from arising by applying the assessment criteria when authorising a planned PV installation.

Well-known examples of problematic reflections from specular building façades include the Vdara Hotel \& Spa in Las Vegas and the "Walkie-Talkie" building in London [4], both of which feature concave façades and required remedial measures such as applying a non-reflective film to the specular surfaces. Another example is the Walt Disney Concert Hall in Los Angeles, whose exterior was sanded down to mitigate reflection [5].

Documented examples of glare specifically from PV reflection include the installation at the Manchester-Boston Regional Airport, which resulted in extremely disabling glare directed towards the control tower [6]. An analysis conducted by the Massachusetts Institute of Technology (MIT) [2] concluded that the existing guidelines issued by the FAA (U.S. Federal Aviation Authority) for evaluating PV at airports are vague and do not consider the sun's variable position over the year. The situation was remedied by reorienting the modules by $90^{\circ}$.

Cases of PV reflection in residential settings are more sparsely documented, and often regional in scope. Several legal settlements over instances of PV glare are summarised by Bohren [7], revealing varying interpretations of the existing legislation governing PV installations in Germany. Similarly, an ongoing neighbourly dispute over glare from a solar thermal collector reveals the inadequacy of the relevant legislation currently in place in Switzerland $[8,9]$.

This paper is organised as follows: Section 2 covers the current state of legislation, assessment criteria and simulation techniques for PV reflections. Section 3 introduces the case study assessed using the proposed methodology. Section 4 details the proposed spatio-temporal simulation and postprocessing workflow, as well as the candidate materials used in the case study. Section 5 presents the results obtained with the proposed methodology and case study by applying assessment criteria, and discusses the implications. Finally, Section 6 draws the conclusions and offers an outlook on future research directions. As a convenience to the reader, Table 1 summarises the nomenclature and symbols used in this paper.

\section{Background}

\subsection{Current Legislation}

The acceptance of BIPV by architects, authorities and communities requires a high degree of flexibility in design, and a form of governance that limits specular reflections from façades. Currently there is in fact a surprising dearth of specific legislation to regulate these potentially disturbing or even disabling effects.

In Switzerland, BIPV in façades and areas of the building envelope except the roof are subject to mandatory approval by building and environmental authorities. Roof-mounted PV that is "adequately adapted" in compliance with article 18a of the federal spatial planning law (Bundesgesetz über die Raumplanung, RPG [10]), is exempt from authorisation. The RPG is implemented for PV installations according to Article 32a of the federal spatial planning ordinance (Raumplanungsverordnung, RPV [11]), which states that roof-mounted PV should (a) appear as homogeneous surface, (b) be of low reflectance in accordance with the state of the art, and (c) not overhang the roof edges.

An informal survey was conducted by the authors with building authorities in four Swiss Cantons (Bern, Basel, Neuenburg/Neuchâtel and Zürich) to determine whether specific requirements for glare protection from BIPV have been established locally. The survey revealed that none of the regional 
authorities currently enforce definite criteria for PV installations beyond those cited in the RPV, and in particular, no specific parameters to identify potential glare from reflections.

The Swiss federal environmental agency (Bundesamt für Umwelt, BAFU) has issued a draft proposal that regulates emissions from artificial lighting and reflections from building façades as well as PV installations, but does not specify actual limits for glare [12]. In fact, the current proposal recommends that, if in doubt, the decision on whether a particular reflection is tolerable or not should be based on subjective expert opinion during an on-site inspection.

Table 1. Nomenclature and symbols used in this paper.

\begin{tabular}{|c|c|}
\hline \multicolumn{2}{|r|}{ Acronyms } \\
\hline BAFU & Swiss federal environmental agency (Bundesamt für Umwelt) \\
\hline BIPV & Building Integrated Photovoltaics \\
\hline BSDF & Bidirectional Scattering Distribution Function \\
\hline HDR & High Dynamic Range \\
\hline LAI & $\begin{array}{l}\text { German federal/state association for pollution control } \\
\text { (Bund/Länder-Arbeitsgemeinschaft für Immissionsschutz) }\end{array}$ \\
\hline PV & Photovoltaics \\
\hline RPG & Swiss federal spatial planning law (Bundesgesetz über die Raumplanung) \\
\hline RPV & Swiss federal spatial planning ordinance (Raumplanungsverordnung) \\
\hline \multicolumn{2}{|r|}{ RADIANCE Tools } \\
\hline falsecolor & Applies linear or logarithmic falsecolour scale to HDR image \\
\hline genbsdf & Generates BSDF from measured data as XML file \\
\hline gensky & Generates sky model for given date/time/location (solar position + optional sky dome) \\
\hline mkpmap & Forward raytracer, generates photon map \\
\hline oconv & Generates simulation model as octree (sky + geometry + materials) \\
\hline pcomb & Modifies/filters HDR image pixels \\
\hline pcompos & Composites multiple HDR images \\
\hline pcond & Tone maps or adjusts exposure of HDR image \\
\hline rcalc & Field-based calculator \\
\hline rcontrib & Source/timestamp contribution raytracer, computes time-series irradiance from photons \\
\hline rtrace & General backward raytracer, computes cumulative irradiance from photons \\
\hline vwrays & Generates primary rays for a given viewpoint to pass into raytracer \\
\hline \multicolumn{2}{|r|}{ Parameters [Units] } \\
\hline $\operatorname{DoY}(\Delta \mathrm{DoY})$ & Day of Year (resp. increment) [day] \\
\hline $\operatorname{HoD}(\Delta \mathrm{HoD})$ & Hour of Day (resp. increment) [h] \\
\hline$\tau_{A}$ & Maximum area of $\mathrm{PV}\left[\mathrm{m}^{2}\right]$ \\
\hline$\tau_{d}$ & Maximum distance to PV [m] \\
\hline$\tau_{L}$ & Maximum reflected luminance from $\mathrm{PV}\left[\mathrm{cd} / \mathrm{m}^{2}\right]$ \\
\hline$\tau_{E}$ & Maximum irradiance on receiver from PV $\left[\mathrm{W} / \mathrm{m}^{2}\right]$ \\
\hline$\tau_{t}$ & Maximum sustained glare duration on any day of the year [h] \\
\hline$\tau_{T}$ & Maximum cumulative glare duration per year $[\mathrm{h}]$ \\
\hline
\end{tabular}

\subsection{Current Technical Guidelines and Assessment Criteria}

A recent review on the problem of reflections from building façades was published in [1], which proposes using glare impact categories as criteria for assessing the reflections. However, the criteria are entirely subjective, and not photometrically quantified. It does, on the other hand, propose radiometric limits to quantify the thermal impact of reflections.

Some technical guidelines to assess light emissions (direct or reflected) have been issued by government agencies $[12,13]$ and trade associations [14]. These guidelines primarily cover the relevant photometric theory and practice (including instrumentation), as well the detrimental effects of light pollution on the environment. Sections specifically dedicated to PV installations define separate criteria for residential and commercial settings, where sensitivities tend to differ. These sections also recommend countermeasures such as (a) occluding the PV with natural barriers such as 
vegetation, (b) reorienting the modules, or (c) using PV with low reflectance, e.g., laminated with satinated frontglass.

While the guidelines do mention specific photometric criteria and limits for assessing glare from light emissions, these are intended as recommendations rather than standards for compliance, and this is explicitly stated. This inherent tolerance can be largely attributed to the highly subjective nature with which individuals perceive reflection as glare.

The German federal/state association for pollution control (Bund/Länder-Arbeitsgemeinschaft für Immissionsschutz, LAI) has issued a report with guidelines to measure, assess, and reduce light emissions [13]. This document explicitly states recommendations, quantifies influencing factors and mentions specific parameters to assess critical emissions from artificial lighting and building façades.

On the basis of [13], Swissolar has issued a guideline with specific criteria relevant to PV installations for practitioners [14]. These criteria, together with their recommended thresholds, are summarised in Table 2. Please note that multiple critical conditions (as defined by exceeding the relevant threshold) reinforce the likelihood of glare. The most pertinent of these criteria in assessing potential glare is the reflection luminance, with the irradiance on a receiver due to reflection as complementary criterion.

Table 2. Recommended PV reflection assessment criteria and thresholds.

\begin{tabular}{|c|c|c|c|}
\hline $\begin{array}{l}\text { Parameter, } \\
\text { Critical Condition }\end{array}$ & Description & $\begin{array}{l}\text { Threshold } \\
\text { Value }\end{array}$ & Units \\
\hline$<\tau_{d}$ & Distance to PV & $\begin{array}{l}50 \text { (commercial) } \\
100 \text { (residential) }\end{array}$ & $\mathrm{m}$ \\
\hline$>\tau_{A}$ & Area of PV & $\begin{array}{l}100 \text { (commercial) } \\
10 \text { (residential) }\end{array}$ & $\mathrm{m}^{2}$ \\
\hline$>\tau_{\omega}$ & Angle subtended by PV at receiver & 7.5 & ${ }^{\circ}$ (degrees) \\
\hline$>\tau_{L}$ & Reflected luminance from PV & $\begin{array}{l}30 \text { (MIT) } \\
50 \text { (Swissolar) }\end{array}$ & $\mathrm{kcd} / \mathrm{m}^{2}$ \\
\hline$>\tau_{E}$ & Irradiance from $\mathrm{PV}$ at receiver & $\begin{array}{l}10 \text { (Sandia Labs) } \\
\approx 16.8 \text { (MIT) } \\
30 \text { (Swissolar) }\end{array}$ & $\mathrm{W} / \mathrm{m}^{2}$ \\
\hline$>\tau_{t}$ & $\begin{array}{l}\text { Maximum sustained glare duration on any } \\
\text { day of the year }\end{array}$ & 30 & $\min$ \\
\hline$>\tau_{T}$ & Cumulative glare duration per year & 50 & hours \\
\hline
\end{tabular}

Swissolar recommends an irradiance threshold of $30 \mathrm{~W} / \mathrm{m}^{2}$ for reflections based on a theoretical maximum direct normal irradiance of ca. $800-1000 \mathrm{~W} / \mathrm{m}^{2}$ at medium altitude (typically higher on an inclined PV panel) and a reflectance of ca. 3-4\% (personal communication with Peter Toggweiler, Senior Technical Consultant for Basler \& Hoffmann, Zürich, 27.03.2018). However, an analysis of glint and glare from solar power plants conducted by Sandia National Laboratories [15] reports that a solar irradiance of only $1-10 \mathrm{~W} / \mathrm{m}^{2}$ at the eye can already lead to temporary blindness and afterimages. This analysis was based on retinal irradiance metrics collated from experimental data. Glint constitutes short-term glare that can be particularly hazardous to air and ground traffic, with recovery times for the aforesaid irradiance range lasting 0.8 to 12 seconds in experiments.

Furthermore, an analysis of disability glare at an airport conducted by the Massachusetts Institute of Technology (MIT) [2] proposes a reflected luminance threshold of $\tau_{L}=30 \mathrm{kcd} / \mathrm{m}^{2}$. This limit is based on the assumption that the eye can accommodate a luminance range of up to two orders of magnitude, given an average indoor luminance of $300 \mathrm{~cd} / \mathrm{m}^{2}$. Using the retinal irradiance metric defined by Sadia National Laboratories [15], the authors concluded that this luminance is likely to cause after-images. Assuming a luminous efficacy of $179 \mathrm{~W} / \mathrm{m}^{2}$ [16], a reflective PV surface area $\tau_{A}=10 \mathrm{~m}^{2}$ and a distance of $\tau_{d}=100 \mathrm{~m}$ for a residential setting according to Table 2, the proposed luminance threshold corresponds to an approximate irradiance threshold of $\tau_{E} \approx 16.8 \mathrm{~W} / \mathrm{m}^{2}$. This, like the limits reported by Sandia National Labs, lies well below the theoretical threshold proposed by Swissolar. 
To reinforce the presented analysis, the luminance resp. irradiance thresholds recommended by MIT and Sandia National Laboratories are included in Table 2. In consideration of the above evidence, and the fact that these thresholds were experimentally derived rather than rooted in theory, an additional, more conservative irradiance threshold $\tau_{E}=10 \mathrm{~W} / \mathrm{m}^{2}$ is applied in assessing the case study simulations to complement the $30 \mathrm{~W} / \mathrm{m}^{2}$ recommended by Swissolar.

\subsection{PV Reflection Simulation}

Reflections from PV are transient in time and space over the course of a year, and thus difficult to predict. A reliable annual prediction on the basis of computational simulation can therefore complement the practitioner's experience in selecting a candidate PV installation. Ideally, this analysis should be applied in the pre-project planning phase of a PV proposal to identify potentially disturbing reflections at an early stage. The results can then lead to adjustments to the project while still in the planning phase. In addition, authorities issuing building permits can base their decisions on the analysis. This avoids incurring additional expenses for subsequent adjustments in the course of the project, or additional consultancy for more elaborate reflection analyses.

There are few documented instances of simulation workflows and tools to specifically assess PV reflection, and they have all been developed in the context of aviation. Jakubiec and Reinhart [2] performed an analysis of disability glare from a PV installation at an airport, reporting reflected luminance levels in excess of $250 \mathrm{kcd} / \mathrm{m}^{2}$ impacting the control tower. These measurements were used to validate an annual simulation of reflected luminance using the RADIANCE lighting simulation software suite [16]. An analytical reflection model of the PV module surface was derived from spectrophotometric measurements and HDR photographs of a sample at oblique viewing angles. Based on their results and a proposed luminance threshold, the authors were able to predict the monthly glare duration.

Fraunhofer FIT developed an interactive system specifically to analyse glint and glare from PV at airports [17]. At the time of writing, this system only considered total specular reflection using an analytical BSDF model, ignoring the potentially significant diffuse component. Furthermore, the system does not consider the topography of the built environment (which is typically flat around airports), nor any of the abovementioned recommended thresholds in its assessment.

The sophisticated Solar Glare Hazard Analysis Tool (SGHAT) developed by Sandia National Laboratories [18] offers a convenient web-based interface using the Google Maps API. The user can select a region populated by PV superimposed on satellite imagery and adjust a multitude of parameters, such as PV tilt, orientation, elevation, and reflectance. The user must then select fixed observation points, for which the tool generates annual glare occurrence plots in three categories-including permanent eye damage-according to the retinal hazard metrics collated by Sandia Labs [15]. Like Fraunhofer's system, SGHAT is primarily aimed at air traffic and satisfies FAA requirements. Unfortunately the tool is now restricted to military, state, and federal government users only, and its support ended in 2017. The SGHAT software is currently being licensed by Sims Industries as part of their ForgeSolar PV glare analysis toolset [19], which incorporates many of the aforesaid features and is available to registered users.

The PV reflection analysis workflow proposed in this paper primarily builds on earlier work by Yang [20], which applied forward raytracing and simplified density estimation techniques to locate reflections from a building façade on a 3D model of its surrounding built environment. This was implemented on a parametric design platform comprised of RHINO and GRASSHOPPER. While the workflow proposed herein also leverages forward raytracing and density estimation, it does so in the unified context of RADIANCE and its photon mapping extension [21]. This work improves on the aforementioned simulation workflows by using data-driven BSDF models of the measured PV samples for a more accurate prediction of both specular and diffuse reflection. Furthermore, the proposed method benefits from the higher quality specular-diffuse reflections obtained with the photon map's forward raytracing algorithm. 


\section{Case Study}

The PV reflection assessment workflow proposed in this paper is demonstrated on a case study of a PV retrofit of a church sited in Lucerne, Switzerland. The church of St. Michael was built in 1967 by the architect Hanns A. Brütsch [22], an award-winning reformer of modern ecclesiastical architecture in Switzerland. The design of St. Michael is an example of beton brut creating sharp-edged expressive building volumes with exposed concrete. The building encloses the patio with an entrance and gathering space while resembling a fortress from the street view. Figure 1 shows the church in its current state in the context of its surroundings.

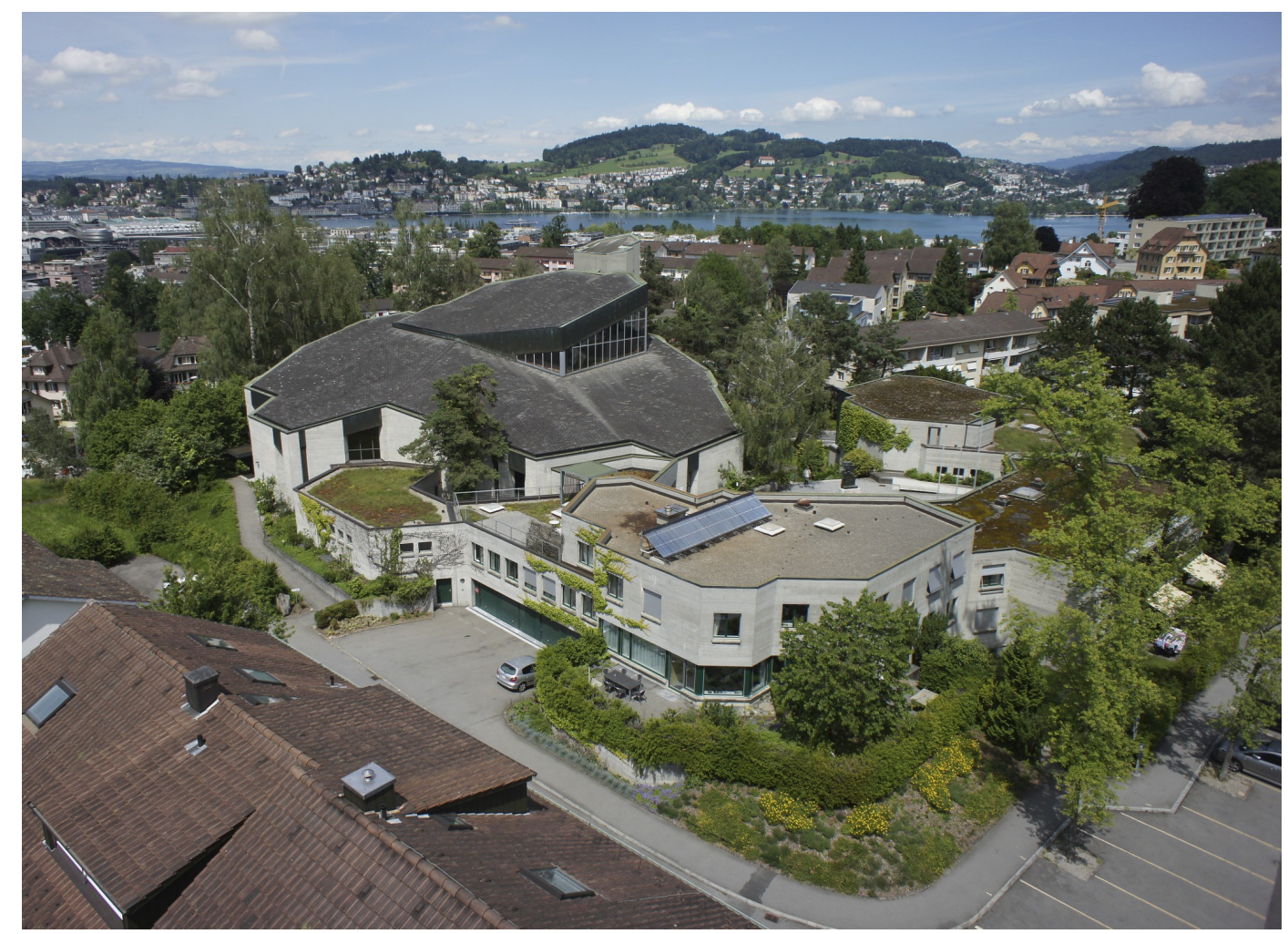

Figure 1. Aerial view of St. Michael's church with parish in foreground, looking northeast.

Figure 2 shows the original site plan. The roof slopes annotated in handwriting indicate the roof sections identified for PV coverage. Two sections face west with a slope of $27 \%$, while one section faces south with a slope of $35 \%$. As such, the heritage board was concerned with disturbing reflections from the proposed roof sections. The proposed PV system installer visualised the zones potentially affected by reflections in Figure 3 but could not make a conclusive verdict on the potential for glare. For this and other reasons, the project was put on hold. There are several large roof spaces, which were up for energy retrofit in 2010. However, being an icon of beton brut, the church is a heritage protected site and as such, retrofit projects must maintain the original materials, construction and appearance. Initial applications to mount PV modules to some parts of the old roof were hence rejected by the municipal heritage board.

A new attempt was made recently, in which the retrofit concept proposed to completely replace three larger roof sections with integrated photovoltaics. The PV roof shall visually maintain the small grained texture of the old roof tiles, and the construction details along eaves and verges shall follow the old dimensions, yet replace timber and fibre cement with metal and glass. In addition, the glare issue should be investigated by computational simulation to make informed decisions about zones and duration of potential glare, taking into account the material properties of different PV frontglass surfaces. 


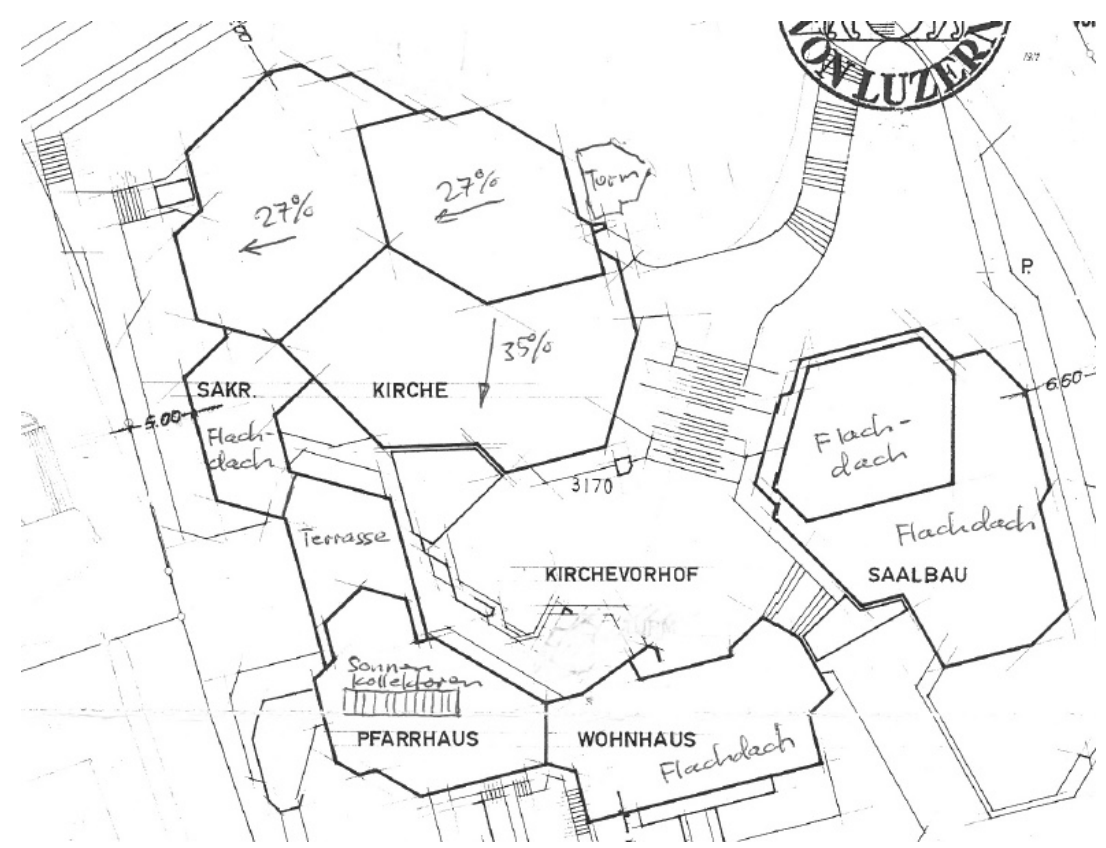

Figure 2. Original roof plan of St. Michael's church indicating slopes of each roof section.

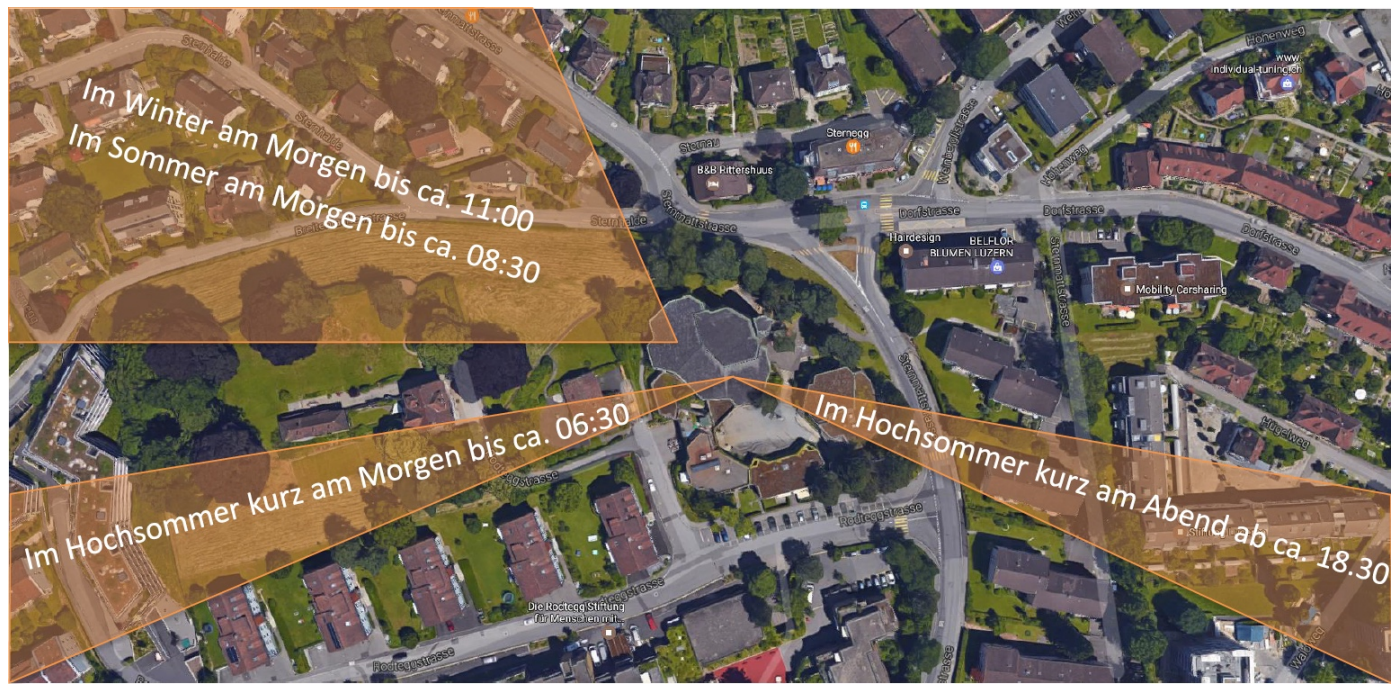

Figure 3. Reflection zones and timespans from roof of St. Michael's church predicted by PV system installer for initially proposed PV roof retrofit. Image courtesy of BE Netz AG.

\section{Simulation Methodology}

\subsection{Motivation}

The primary objective of the proposed simulation methodology is to provide a visual prediction of potential glare zones in the context of the built environment around a planned BIPV installation. While luminance is generally the preferred criterion for identifying glare, it is unfortunately dependent on viewpoints facing the emitting building. These must be fixed for each simulation run, possibly requiring multiple iterations. Viewpoint placement requires a priori knowledge or anticipation of where glare is likely to occur on behalf of the planner.

The irradiance on the built environment, on the other hand, can be rendered in one image to concisely convey areas of potential glare as seen from the emitting building. This provides an initial qualitative overview that fundamentally clarifies the presence or absence of potential glare as a first 
step in planning a PV installation. This saves the planner the burden of selecting observation points for a more comprehensive luminance analysis, e.g., in order to apply glare probability metrics. Such an analysis would then only be warranted for selected zones indicating potential glare.

The proposed approach is therefore entirely image-based, with irradiance resolved spatially and temporally as a time-series of rendered high dynamic range (HDR) images, which are referred to as irradiance maps. This time-series typically encompasses a simulated half-year due to analemmatic symmetry, and can be condensed into a single representative image, since a planner is generally not interested in assessing individual point-in-time data, but the aggregate annual result. The visualisation should therefore convey the latter by reducing the 3-dimensional spatio-temporal time-series to a 2-dimensional composite image. In doing so, the irradiance can be evaluated according to the recommended criteria in Table 2 to identify glare and obtain the maximum sustained and cumulative glare durations per year, which are quantified with a falsecolour scale. Thus only the essential data is presented, making the visualisation suitable for non-expert clients and decision makers who may review the results during the building permit application process.

Because only PV reflections are to be assessed, irradiance from other sources-notably the direct component from the sun-is not falsecoloured, but composited into the visualisation in greyscale to aid in orientation and identify affected buildings in the environment. The proposed workflow follows from this, and the direct and PV reflection irradiance maps are rendered separately, with the latter falsecoloured before being composited with the former. More importantly, this also avoids false glare in panoramic views, since the sun paths are visible in the direct irradiance maps.

Each irradiance map in the time-series is rendered using RADIANCE in photon mapping mode. Because photon mapping traces rays from the light sources (suns) towards the receivers (built environment), it excels at simulating specular-diffuse transfers, or caustics. Depending on its specularity, the PV surface material can effectively redirect daylight towards the built environment as caustics. Photons are deposited and stored on the surrounding diffuse surfaces, and may be reused for subsequent renderings. The RADIANCE photon map also supports time-series renderings by tagging each photon with its emitting light source (sun position) [21].

In addition to an efficient light transport algorithm, reliably predicting the irradiance reflected from PV also requires an accurate representation of the PV's reflecting behaviour. This is particularly important for standard PV modules with a glossy surface finish, which exhibit significant specular reflection. Consequently, the case study simulations use a data-driven representation derived from measurements of actual candidate PV samples.

\subsection{Workflow Overview}

The proposed methodology consists of two workflows to visualise irradiance from PV reflection: a general workflow to assess cumulative annual irradiance, summarised in Figure 4, and a spatio-temporal workflow to assess glare duration according to recommended criteria, summarised in Figure 5. The latter builds on the former by using some of its output (photon map, simulation model, timesteps) and lies at the heart of the methodology.

Both workflows are managed in a UNIX Makefile which handles the multiple dependencies (corresponding to arrows in the flowcharts) and selectively runs individual components as targets. A separate simulation is run (technically an invocation of the Makefile) for each candidate PV material.

Table 3 lists the simulation parameters chosen for the PV reflection case study. These coincide with the inputs shown on the left side of the general workflow overview in Figure 4. The workflow components are detailed in the following subsections. 


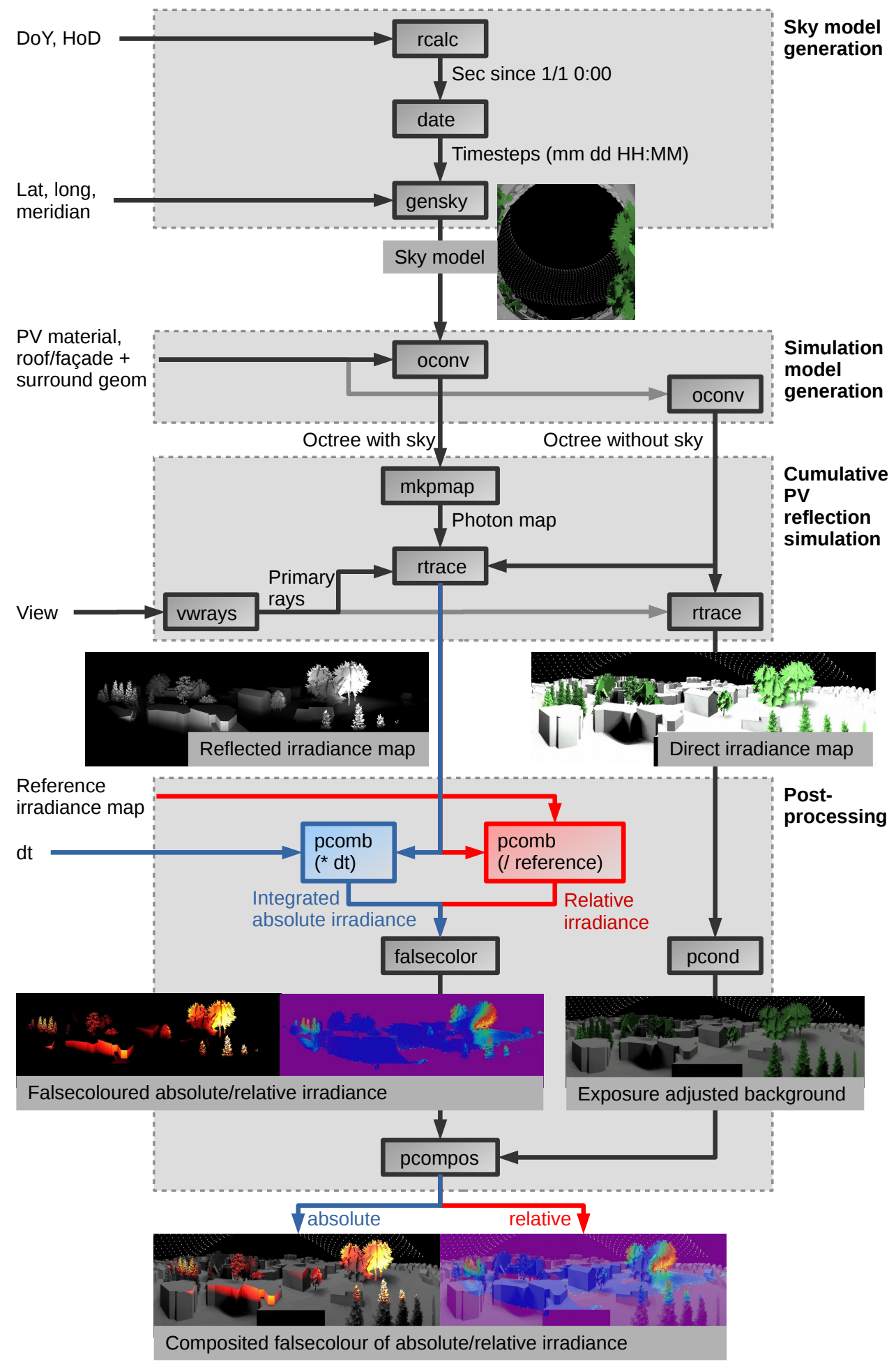

Figure 4. General PV reflection simulation workflow to assess cumulative annual irradiance. 


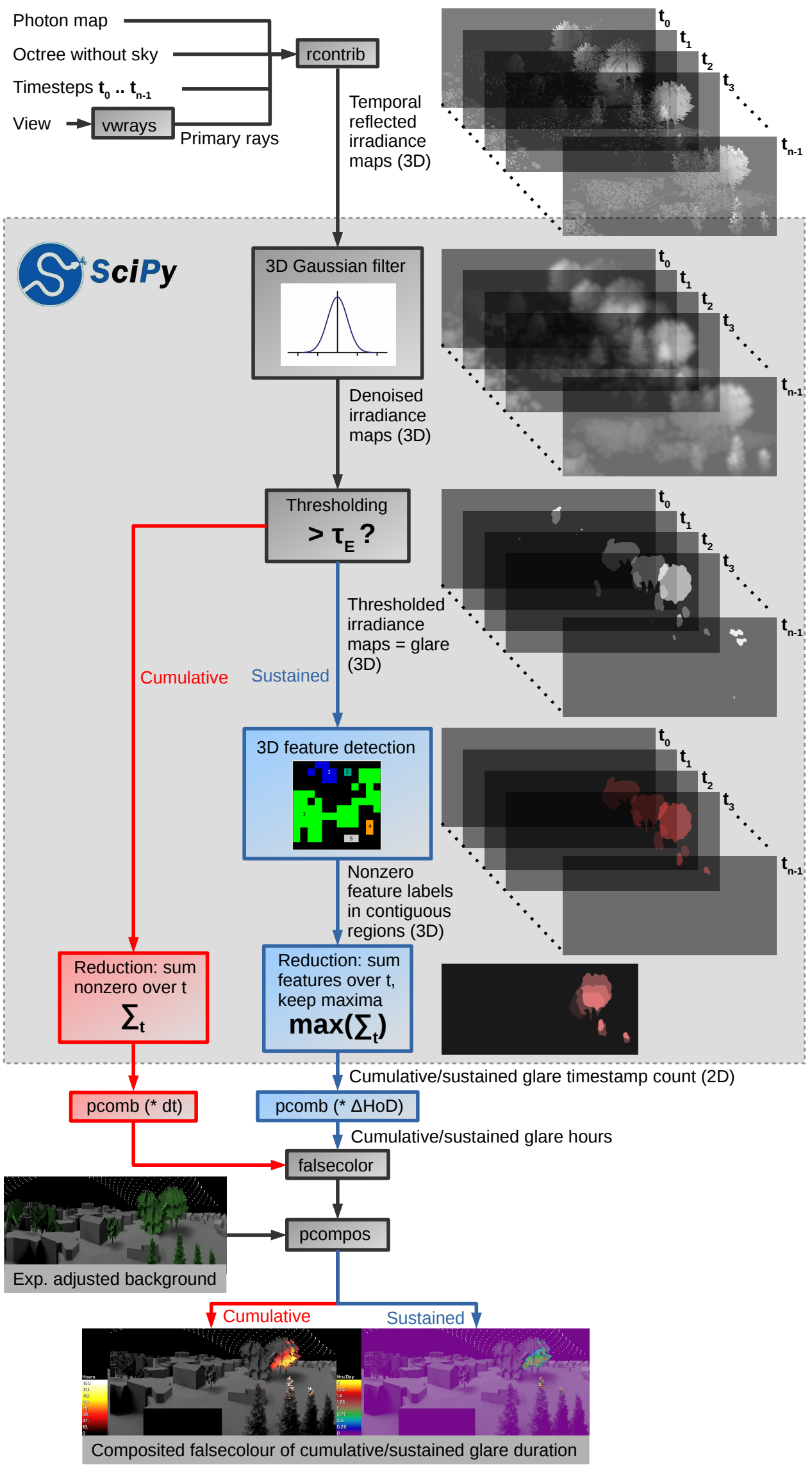

Figure 5. Spatio-temporal PV reflection simulation workflow to assess glare duration. 
Table 3. Simulation parameters for PV reflection case study.

\begin{tabular}{ccc}
\hline Parameter & Description & Value \\
\hline DoY & Day of year & {$[0,181]$} \\
$\Delta \mathrm{DoY}$ & Day of year increment & 7 \\
$\mathrm{HoD}$ & Hour of day & {$[4.5,20.5]$} \\
$\Delta \mathrm{HoD}$ & Hour of day increment & 0.25 \\
$N_{t}$ & Number of timesteps (sun positions) & 1280 \\
Lat, long & Site latitude, longitude & $47.038^{\circ} \mathrm{N}, 8.312^{\circ} \mathrm{E}$ \\
Merid & Timezone meridian & $15^{\circ} \mathrm{E}(\mathrm{CET})$ \\
$N_{p}$ & Number of photons & $250 \mathrm{M}$ \\
$n_{p}$ & Photon lookup bandwidth & 400 (rtrace) $), 4000$ (rcontrib) \\
\hline
\end{tabular}

\subsection{General Workflow}

The general workflow summarised in Figure 4 generates the timesteps, corresponding sky model and octree for the simulation. Furthermore, it simulates PV reflection by generating a photon map representing the incident flux on the built environment. These intermediate results are also used for the spatio-temporal workflow to apply criteria and evaluate glare duration.

The workflow visualises cumulative annual irradiance in absolute units $\left(\mathrm{Wh} / \mathrm{m}^{2}\right)$, and as ratio in relation to a reference material. The latter is primarily intended to compare the irradiance distribution of proposed and existing candidate materials. Both absolute and relative workflows share common components (shown in grey in Figure 4). Components specific to evaluating absolute irradiance are highlighted in blue, while those specific to relative irradiance are highlighted in red.

This simulation workflow is comprised of four stages: sky model generation, simulation model generation, cumulative PV reflection simulation, and postprocessing. These are detailed in the following subsections.

\subsubsection{Sky Model Generation}

In the initial simulation stage, timesteps are generated in fixed intervals, enumerated as day of year (DoY) since Jan. 1st, and local hour of day $(\mathrm{HoD})$ for the current DoY. DoY and HoD are incremented by $\Delta \mathrm{DoY}$ days and $\Delta \mathrm{HoD}$ hours, respectively, with the latter being fractional. See Table 3 for timestep ranges and increments used in the case study.

Please note that DoY increments can be coarse, as the sun paths progress very slowly on a daily basis. By contrast, sun paths change rapidly over the course of a day, and $\mathrm{HoD}$ is sampled densely. According the Nyquist Theorem, the latter should be sampled in at least 15-min intervals to adequately resolve the maximum sustained glare duration threshold $\tau_{t}$ of $30 \mathrm{~min}$ in Table 2.

DoY and HoD are converted to absolute seconds with RADIANCE's rcalc utility and passed as seconds since the Epoch (Jan. 1st 1970 UTC) into the UNIX date utility, which generates the corresponding date and time in UTC. These timesteps are passed to RADIANCE's gensky tool to generate corresponding sky models. The timesteps are converted to local time for the specified timezone, latitude and longitude of the site under investigation.

Similarly to the RADIANCE simulations for MIT's PV reflection analysis [2], a worst case scenario is assessed by generating a sunny sky consisting only of a distant light source representing the sun's position, without cloud cover. Solar sources for each timestep are accumulated in a RADIANCE sky model file, with the exception of sun positions below the horizon (notably in the very early and late winter hours); these are ignored by gensky. With the DoY and HoD parameters in Table 3 this results in 1280 timesteps / sun positions. These are shown in a hemispherical projection facing the zenith as seen at the site under investigation in Figure 6. Please note that due to analemmatic symmetry, it suffices to simulate half a year, hence DoY is limited to 181. The second half of the year is compensated for by suitably weighting the accumulated irradiance during postprocessing, as described in Section 4.3.4. 


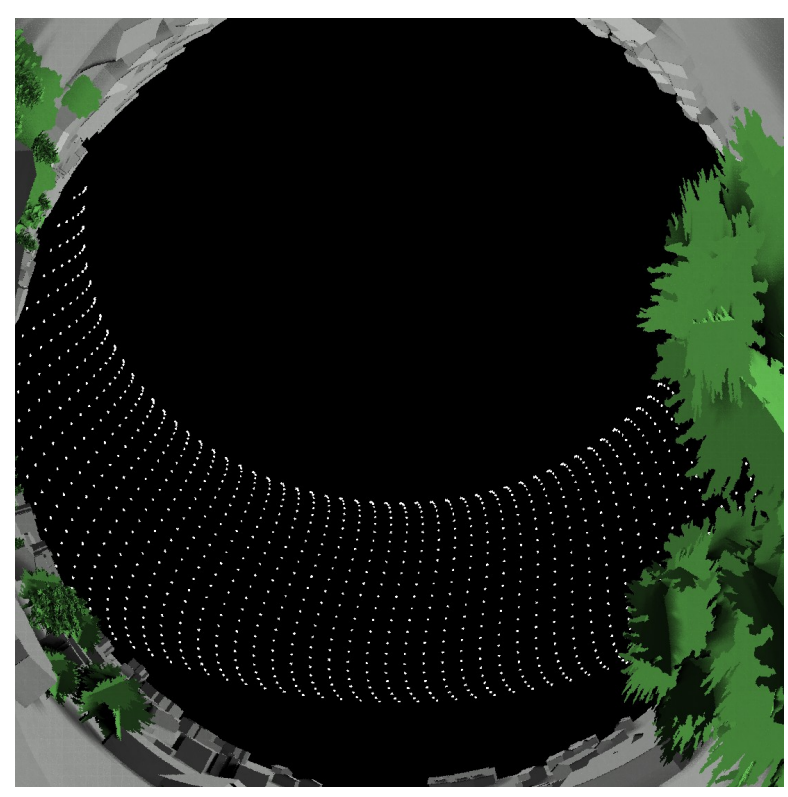

Figure 6. Fisheye view (hemispherical projection) of sunny sky model with 1280 timesteps as seen from the roof of the case study, with south in the lower centre.

\subsubsection{Simulation Model Generation}

The simulation model consists of the geometry of the site under investigation (roof or façade) as well as its immediate surroundings, at least within a radius of $100 \mathrm{~m}$ according to the recommended threshold $\tau_{d}$ in Table 2. In addition, PV material models are a critical ingredient; these should be reasonably accurate in modelling the scattering behaviour of the proposed candidate PV modules to obtain a realistic assessment of the reflection. Both simulation components are detailed in the following subsections.

The geometric and material models are distilled along with the previously generated sky model into a RADIANCE scene octree with the oconv tool. Since the proposed analysis primarily concerns the reflected component from the PV, this component is processed separately. Since RADIANCE offers no immediate option to exclusively render this component, an additional octree without sky model is generated; in conjunction with the RADIANCE photon mapping extension, this can be used to only render the indirect irradiance from PV reflection. The octree with sky is used to render the direct component, which is used as background for visualisation during postprocessing.

\section{Geometric Model of Church and Surroundings}

The authors obtained a digital terrain model of St. Michael's church and its built environment from the Geographic Information System of the Canton of Lucerne (GIS Kanton Luzern) [23]. This model was extracted from point cloud data obtained from LIDAR scans and is available to the public. Trees in the immediate environment of the church were identified from photographs and satellite images, and added with the RHINO 3D modelling software. In addition, minor corrections to the church roof geometry were made by hand based on the original blueprints. The entire geometry was then exported with RHINO to the RADIANCE format for the simulation. All surfaces other than the church roof were assigned Lambertian materials with $25 \%$ reflectance.

\section{Candidate PV Material Models}

Samples of the proposed PV modules as well as the existing roof tiles were obtained from the manufacturers. The samples included a standard PV module exhibiting glossy reflection, and a satinated module with pronounced diffuse scattering more closely resembling the existing roof tile in appearance (see photographs in Figure 7). All three samples were analysed in terms of their scattering 
behaviour for the simulation. To this end, each sample was measured in a goniophotometer to obtain its BSDF (Bidirectional Scattering Distribution Function) [24], which was observed to be isotropic in all cases. Figure 8 shows polar plots of the measured PV BSDFs for two incident directions, with the existing roof tile BSDF superimposed as reference.

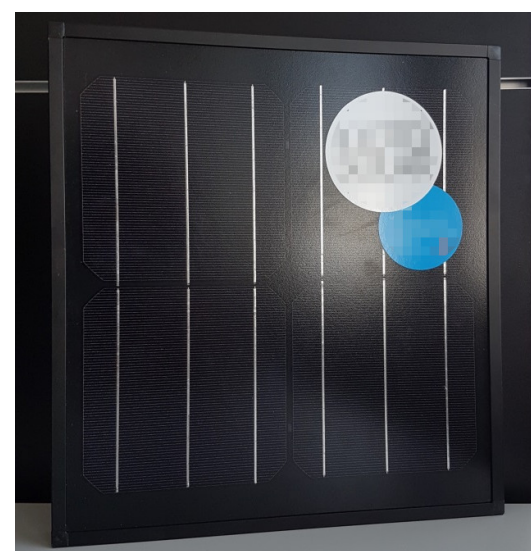

(a) Standard PV

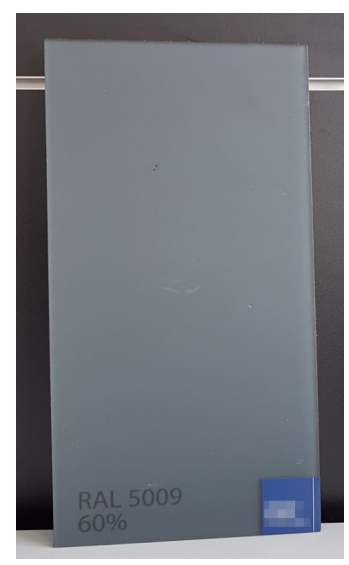

(b) Satinated PV

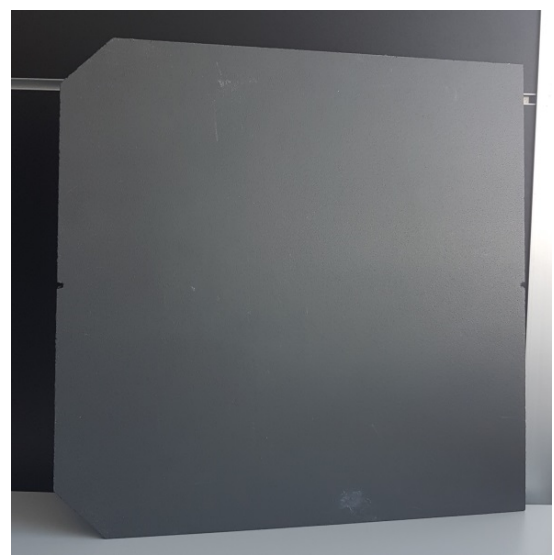

(c) Existing roof tile

Figure 7. Photographs of material samples used in the case study: standard PV (a), satinated PV (b), and existing roof tile (c).

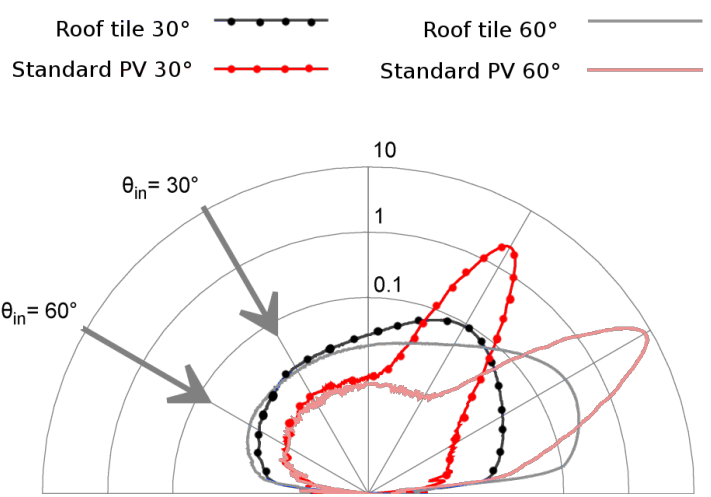

(a) Standard PV (red) vs. roof tile (grey)

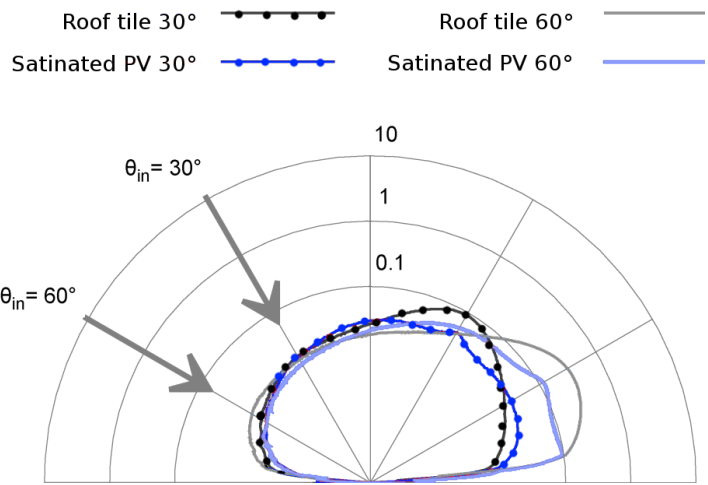

(b) Satinated PV (blue) vs. roof tile (grey)

Figure 8. Polar BSDF plots of standard (a) and satinated (b) PV modules for incident angles of $30^{\circ}$ and $60^{\circ}$. Corresponding BSDF plots of the existing roof tile are superimposed for reference.

The candidate PV materials were modelled with the data-driven bsdf material primitive in RADIANCE, which reads the data from an XML file. The XML format describes a variable-resolution tensor tree representation of BSDF data [25], which is output by the genbsdf tool. The resulting data driven BSDF model has an angular resolution of up to 128 directions in the incident plane, and $128 \times 128$ in the exitant hemisphere. The resolution was adaptively reduced by thresholding the least significant $80 \%$ of data.

Figure 9 shows falsecolour RADIANCE luminance renderings of the data-driven BSDF models applied to the roof of the case study model. The renderings convey the appearance of the PV roof and the different scattering characteristics of the material models subject to the time of day. As expected from the BSDF plots, both the existing roof tile and satinated PV module exhibit predominantly diffuse scattering. On the other hand, the standard PV module exhibits pronounced specular reflection, particularly on summer mornings, conspicuously diverging in appearance from the original roof. 


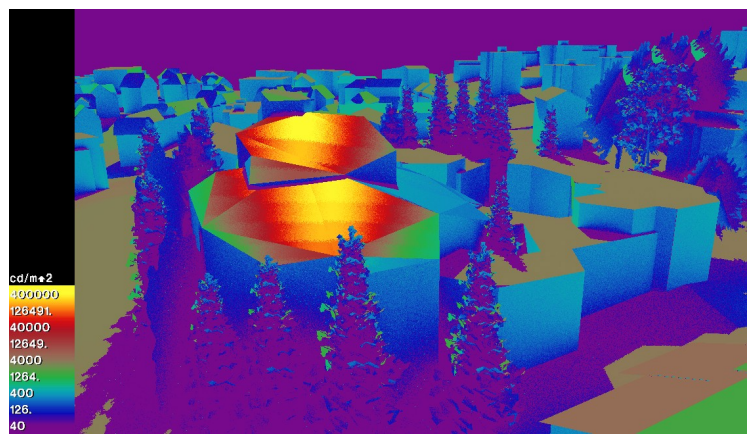

(a) Standard PV at 8:30 a.m.

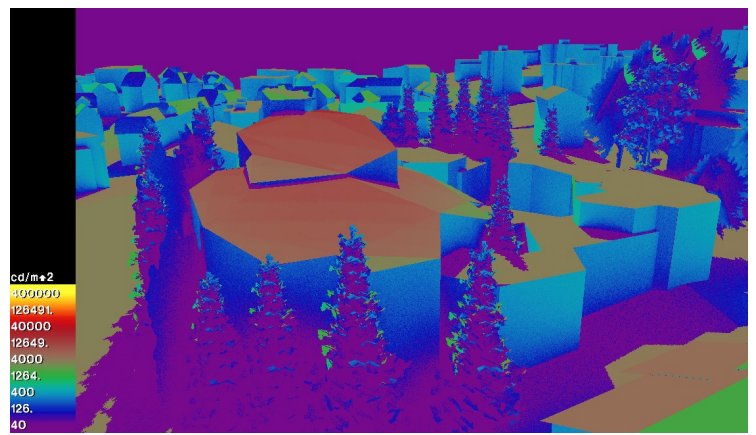

(c) Satinated PV at 8:30 a.m.

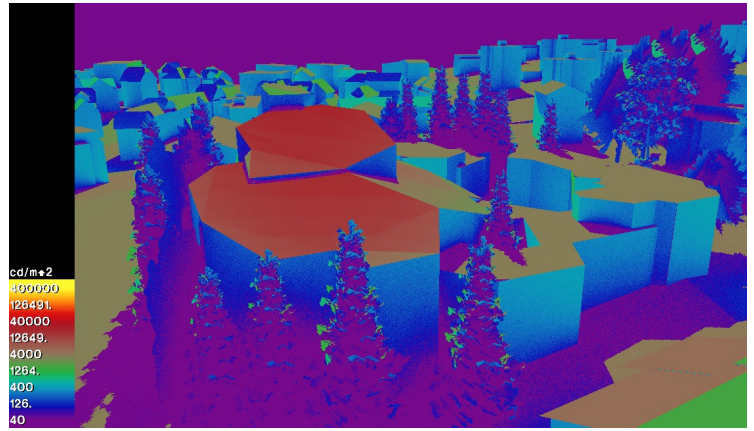

(e) Existing roof at 8:30 a.m.

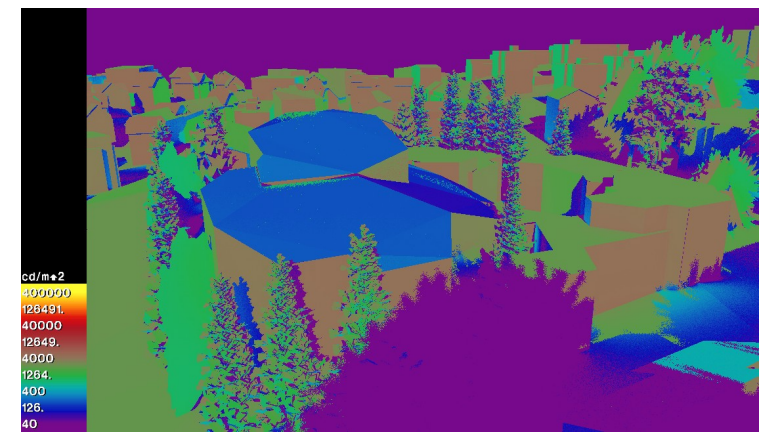

(b) Standard PV at 5:30 p.m.

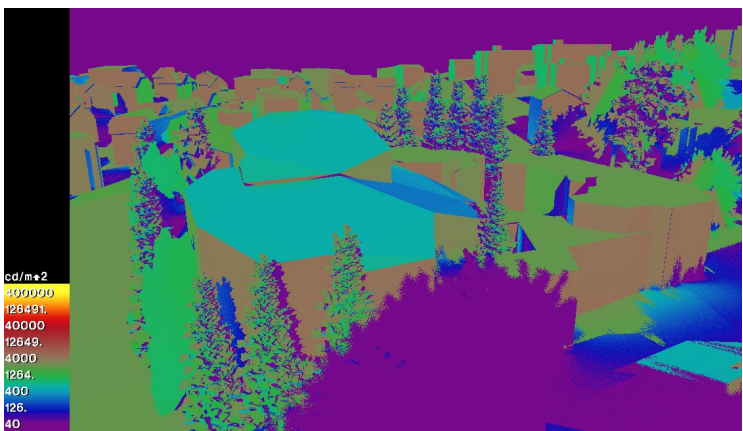

(d) Satinated PV at 5:30 p.m.

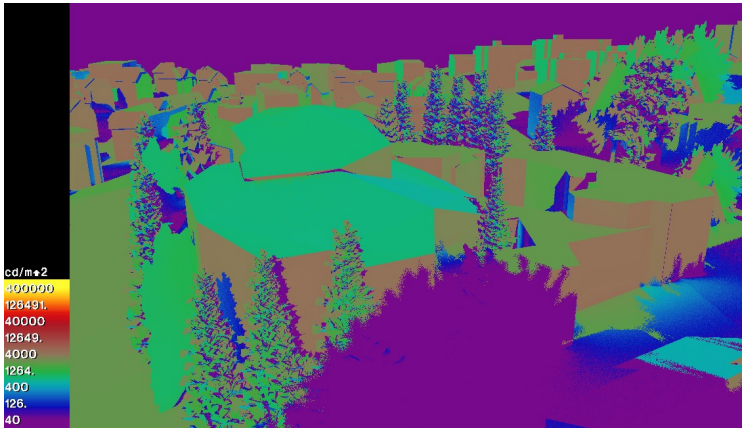

(f) Existing roof at 5:30 p.m.

Figure 9. Falsecolour luminance renderings of the case study model looking east on June 11th at 8:30 a.m. (a,c,e) and 5:30 p.m. (b,d,f). The roof material is modelled as a data-driven BSDF for the standard PV $(\mathbf{a}, \mathbf{b})$, satinated PV $(\mathbf{c}, \mathbf{d})$, and existing roof tile $(\mathbf{e}, \mathbf{f})$. The distinct scattering behaviour of each BSDF is evident at different times of day.

\subsubsection{Cumulative PV Reflection Simulation}

The previously generated octrees (with and without sky) containing the simulation models are the basis for the PV reflection simulation. Flux transport within the model is precomputed by generating a photon map, which is then subsequently rendered to evaluate the irradiance on the environment. Both steps are explained in the following sections.

\section{Photon Map Generation}

The proposed workflow uses the RADIANCE out-of-core photon mapping extension [21,26] developed specifically to efficiently simulate specular redirection with very large photon maps. Out-of-core techniques enable paging photons on demand from disk, and maintain an active subset of these in-core in a custom cache. In addition, contribution photons are used to identify flux originating from individual sun positions corresponding to the timesteps to render the time-series irradiance maps in the spatio temporal workflow (see Section 4.4). 
The contribution photon map is generated with the mkpmap tool and written to a separate file for subsequent rendering by rtrace or rcontrib. The photon map represents the precomputed light transport from the PV material onto the surrounding surfaces and can be reused for multiple renderings. Mkpmap leverages the parallelism inherent in photon tracing since all photon paths are independent.

Several optimisations are employed to reduce the photon count to the minimum required for the simulation, at the expense of increased photon distribution time (ca. $4 \mathrm{~h}$ on an 8-core system with the case study). The photon transport is limited to a single forward scattering event from the PV surfaces onto the surroundings with mkpmap's -lr 1 option [27]. This forces mkpmap to disregard secondary photon reflections by terminating the photons prematurely. The rationale for this optimisation is that secondary reflections are negligible as long as the surroundings are diffuse.

In addition, the photon paths are limited to a cumulative length of $100 \mathrm{~m}$ with the -ld 100 option, in accordance with the recommended criterion $\tau_{d}$ in Table 2 for a residential zone. Photons are again terminated beyond this distance, thus limiting their footprint to the region of interest. Acceptable results (in terms of noise) can thus be obtained with a moderate number of photons.

Lastly, photon ports [27] are used to emit photons directly onto all PV surfaces (in this case, the roof), disregarding reflections from exterior walls or the surroundings. To this end, photons are displaced a small distance along the sun vector from the PV surfaces, and emitted towards them. Irregularly shaped polygons, as in the case of the roof of St. Michael's are handled via rejection sampling.

\section{Rendering}

PV reflections are rendered as a separate component using the previously generated photon map and RADIANCE octree without sky, thus omitting the direct component. The irradiance from the PV reflection onto the surroundings is evaluated via photon density estimates from the previously generated photon map with rtrace. This general raytracing tool in the RADIANCE suite supports parallel raytracing and can be used for rendering by passing in primary rays from a view via vwrays. The renderings are then output as RADIANCE HDR images. These are then postprocessed for visualisation of the reflected component as described in the following section.

The direct component is also rendered with vwrays / rtrace but using the octree with sky. The indirect (reflected) component is omitted by setting zero ambient bounces with the $-a b 0$ option. The resulting direct irradiance map serves as background for the subsequent postprocessing.

Please note that renderings are generated from two representative perspectives: a plan view as an overview for context, with the site under investigation in the centre, and a cylindrical projection as $360^{\circ}$ panoramic view from the roof. The latter aids in identifying "hotspots" on adjacent buildings, as well as their corresponding directions. A fore clipping plane was used to prevent the church geometry from occluding the foreground.

\subsubsection{Postprocessing}

In the postprocessing phase, the rendered PV reflection irradiance maps are evaluated. For the absolute annual irradiance, Wh (Watt-hours) are derived from the reflected irradiance on the built environment. For the relative annual irradiance, a unitless ratio of reflected irradiance to that of the (previously rendered) reference case is derived in order to compare the reflection distribution in the environment. Both evaluation modes are detailed in the following subsections.

In both cases, the reflected irradiance map is falsecoloured and composited with the direct irradiance map. The latter is attenuated beforehand by pcond using the $-e$ (exposure) option to provide a background for the visualisation to aid in orientation; it does not convey radiometric data.

\section{Absolute Annual Irradiance}

To evaluate the absolute annual irradiance from PV reflection, the raw reflected irradiance data (consisting of cumulative irradiance proportional to the number of simulated timesteps) is multiplied 
with an annual integration factor $d t$. This is done by scaling the HDR pixels in the reflected irradiance map by $d t$ using the pcomb utility. Given timesteps spanning half a year (DoY $\in[0,181])$, the annual integration factor $d t$ to obtain the cumulative irradiance in Watt-hours [Wh] is approximated by:

$$
d t \approx 2 \Delta H o D \cdot \Delta D o Y
$$

where the factor 2 compensates for the symmetric second half of the year. The accuracy of the integrated annual irradiance obviously depends on the increments $\triangle H o D$ and $\triangle D o Y$; smaller increments (and consequently more timesteps) will result in a finer grained simulation and more accurate results, at the expense of longer simulation and postprocessing times.

\section{Relative Annual Irradiance}

To visualise the reflected irradiance distribution in relation to that of a reference case, the reflected irradiance map pixels are divided by those in the reference irradiance map (obtained from a previous simulation run with the reference material) using pcomb. The ratio is clamped to zero for pixels with zero irradiance (typically in peripheral or occluded areas, where no photons were deposited), thus avoiding division by zero. The resulting image is unitless, with values above 1 indicating the PV reflection exceeds that of the reference, and values below 1 indicating the inverse.

\subsection{Spatio-Temporal Workflow}

The spatio-temporal workflow summarised in Figure 5 follows from the general workflow and reuses its generated simulation model, photon map, and timesteps. From these, it simultaneously renders temporal reflected irradiance maps for each timestep using the RADIANCE rcontrib tool. The photon map supports the association of flux contributions with individual solar sources (and corresponding timesteps) in order to evaluate the constituent irradiance at each timestep. As in the general workflow, the irradiance maps are rendered with an octree without sky to only visualise the reflected component; the direct irradiance map is reused here again as background for compositing the visualisation.

The goal of this workflow is to assess glare duration as primary criterion for identifying problematic glare zones, where glare is defined as reflected irradiance exceeding the threshold $\tau_{E}$ in Table 2. The output is a visualisation of the cumulative glare duration (as isolated events) over the course of a year, as well as the maximum sustained glare for any day of the year. The latter is derived from the maximum number of contiguous timesteps for which the irradiance exceeds the threshold without interruption. This implies temporal contiguity, which the proposed workflow identifies using feature detection. As with the general workflow, both outputs share common components (shown in grey in Figure 5), and those specific to cumulative glare duration are highlighted in red, while those specific to sustained glare are highlighted in blue.

The postprocessing in this workflow is considerably more elaborate and mostly implemented with a Python script using the ndimage multi-dimensional image processing submodule as part of the SciPy scientific computing library [28]. The script processes a chronological time-series of irradiance maps as a 3-dimensional volume (2D matrices with an additional temporal dimension).

The spatio-temporal postprocessing of the time-series irradiance maps consists of four main steps (five for sustained glare): filtering, thresholding, feature detection (for sustained glare), reduction, and visualisation. These are detailed in the following subsections.

\subsubsection{Filtering}

The 2D reflected irradiance maps rendered by rcontrib for each timestep are read from disk by the SciPy script and stacked in chronological order to form a spatio-temporal irradiance volume represented as a 3D matrix. Due to memory constraints and the high resolution of the irradiance maps, 
the timesteps will typically only encompass a single day, although the method would in principle work on the entire annual set of timesteps.

As the reflected irradiance maps are the result of Monte-Carlo raytracing with sparse photon distributions in dark areas, they exhibit considerable noise, which can lead to unwanted temporal and spatial fluctuations after thresholding that break up potentially contiguous regions. The noise is reduced with a 3D Gaussian filter, thus improving temporal continuity and stabilising the subsequent thresholding. While this leads to a loss in detail, it instead emphasises large patches of glare, which is in fact desirable for the intended result.

\subsubsection{Thresholding}

As the main criterion for identifying glare, the filtered pixel in the irradiance volume is compared against the recommended threshold $\tau_{E}$ in Table 2. This results in a binary value for each pixel indicating whether its corresponding irradiance is below or above the threshold; a nonzero value thus indicates the presence of glare according to $\tau_{E}$. Please note that although the pixels assume integer values, the ndimage library still treats the data as floating point, at the expense of increased memory consumption.

\subsubsection{Feature Detection (Sustained Glare)}

When assessing sustained glare, the proposed workflow must identify neighbouring, i.e., contiguous, instances of glare along the spatial and temporal axes. This entails isolating regions of consecutive nonzero pixels (categorised as glare in the previous step) via feature detection. A method typically used in computer vision, feature detection attaches nonzero labels to neighbouring pixels. By applying this in three dimensions, it also accounts for temporal contiguity. The output is a new volume with nonzero integer labels in pixels categorised as glare over multiple consecutive timesteps. Each feature corresponds to a separate glare event and has a unique label.

\subsubsection{Reduction}

In this step, the 3D thresholded irradiance volume is reduced to a single 2D image for visualisation. For the cumulative glare duration, this entails simply summing the thresholded binary pixel values over the temporal axis.

For sustained glare, however, this entails summing (i.e., counting) all instances of pixels with nonzero labels along the temporal axis. The pixels' actual values are disregarded, since these are unique for each contiguous region identified by the feature detection. In addition, disjunct features may overlap in time, e.g., if a pixel experiences several glare events in the course of a day from multiple PV surfaces. To account for this, only the maximum number of nonzero pixels from all features is accumulated, since a planner is primarily interested in assessing the longest glare duration as worst-case scenario.

The output of both reductions is a $2 \mathrm{D}$ matrix containing an integer count of the number of timesteps corresponding to the cumulative or sustained glare duration. This is weighted accordingly in the final step of the workflow. In preparation for this, the matrices are written back to disk as RADIANCE HDR images by the SciPy script, at which point it terminates.

As mentioned above, the current workflow processes daily irradiance maps, consequently the resulting HDR images must be accumulated for the entire simulation run; this entails another level of reduction (accumulating maxima in the case of sustained glare) in a separate Python script, which is not shown in Figure 5.

\subsubsection{Visualisation}

The final step in the proposed spatio-temporal workflow entails scaling the glare duration timestep count in the reduced HDR images, falsecolouring them, and compositing them with an attenuated background image of the direct irradiance as in the general workflow. 
As in Section 4.3.4, the HDR images containing cumulative annual timestep counts are scaled with the annual integration factor $d t$ (Equation (1)) with RADIANCE's pcomb tool, resulting in cumulative annual glare duration in hours. For sustained glare, however, the HDR images are scaled with the hourly timestep increment, $\Delta H o D$, to arrive at the corresponding maximum glare duration for any day of the year, in hours.

\section{Results and Discussion}

\subsection{Annual Reflected Irradiance}

It is already evident from Figures 8 and 9 that the candidate PV module BSDFs exhibit divergent scattering behaviour; while the standard PV is characterised by significant glossy reflection, the satinated PV is noticeably diffuse, and closely resembles the scattering behaviour of the original roof tile. This disparity is corroborated in the simulation results from the case study.

Figure 10 shows plan views of the absolute cumulative annual irradiance reflected from the two candidate PV samples and existing roof tile.The church model with simulated roof material is located in the centre. Note the irradiance scale (Watt-hours) is logarithmic, and only applies to the falsecoloured reflected component. The direct component is composited as background for orientation to identify potentially affected buildings in the environment.

The reflection distribution in relation to the existing roof tile is shown in Figure 11. The reflected component is again falsecoloured, this time on a linear scale as ratio of the annual reflected irradiance from the candidate PV divided by the annual reflected irradiance from the existing roof tile. The red/yellow regions (ratio >1) indicate directions in which the PV reflects more intensely than the roof tile, while the blue regions (ratio $<1$ ) indicate subdued PV reflection compared to the roof tile. Regions with zero reflection (due to occlusion or because they lie outside the zone of influence) are coloured magenta.

Figure 12 shows both the cumulative annual irradiance and relative reflection distribution as cylindrical panorama view from the church roof. The view faces south in the centre, while the left and right edges wrap around and face north. The sun paths comprising the sky model for the simulated half-year are clearly visible above the horizon (although they are absent in the reflected irradiance maps). Part of the parish adjacent to the church can be seen in the foreground, while the church itself is clipped by the fore clipping plane so as not to occlude the view.

These visualisations provide a PV planner with a concise overview of the reflective distributions of candidate PV materials over the course of a year, and which neighbouring buildings are potentially subjected to glare. It is obvious from these results that the standard PV exhibits a pronounced heterogeneous reflection distribution, with a prominent hotspot towards the west, while the satinated PV exhibits more homogeneous reflection, on par with the existing roof tile used as reference. While the hotspot is present in all renderings, it varies in intensity depending on the roof material. For the standard PV, the absolute cumulative annual irradiance shown in Figure 12 peaks in this zone at ca. $3000 \mathrm{Wh} / \mathrm{m}^{2}$, but only at ca. $1000 \mathrm{Wh} / \mathrm{m}^{2}$ for the satinated PV. Please note that this hotspot coincides with a group trees shielding a 2-storey chalet behind them, as can be observed left of the plan views in Figures 10 and 11. This hotspot dominates in the early mornings in June, when the trees bear foliage. This is confirmed by the rendered luminance maps for 11 June at 8:30 a.m. in Figure 9a,c,e, looking east from the approximate position of the hotpot. Please note that the luminance from the standard PV module far exceeds the recommended threshold $\tau_{L}$ of $50 \mathrm{kcd} / \mathrm{m}^{2}$ in Table 2, correlating with the potential for glare indicated by the irradiance map. 


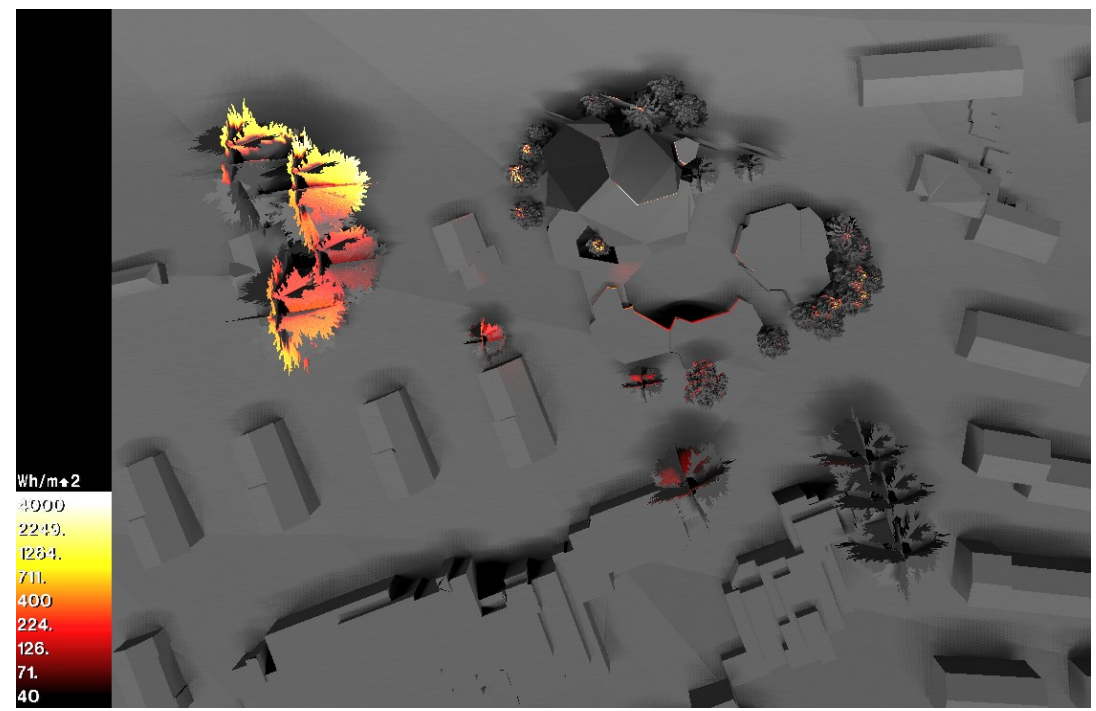

(a) Standard PV

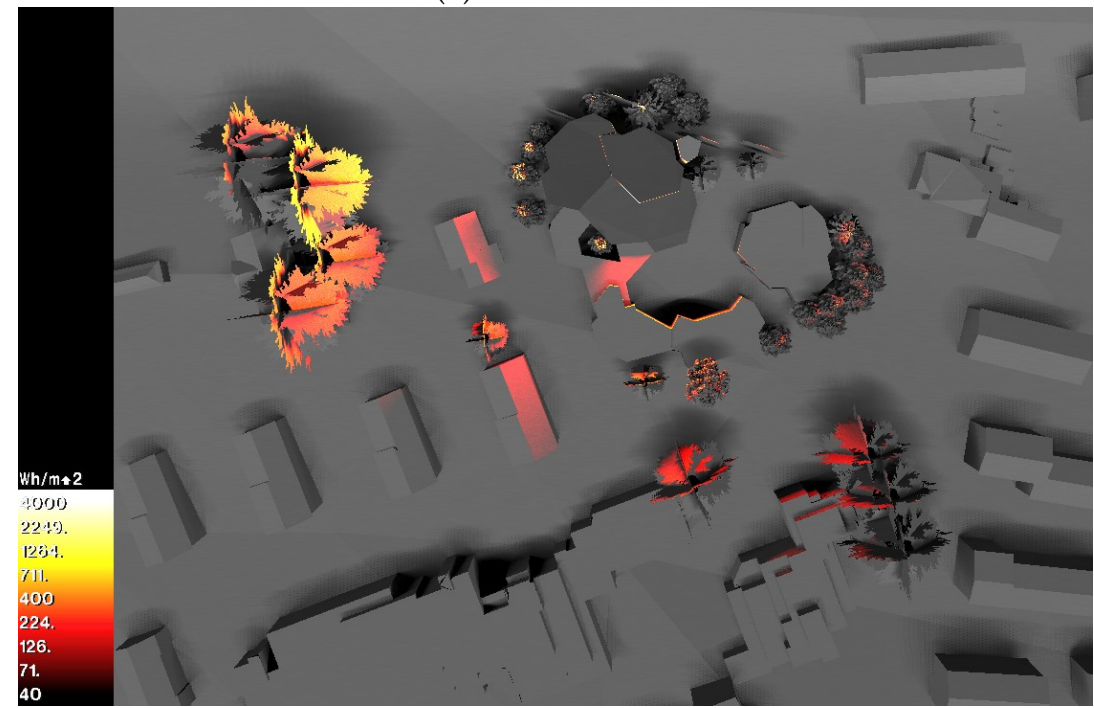

(b) Satinated PV

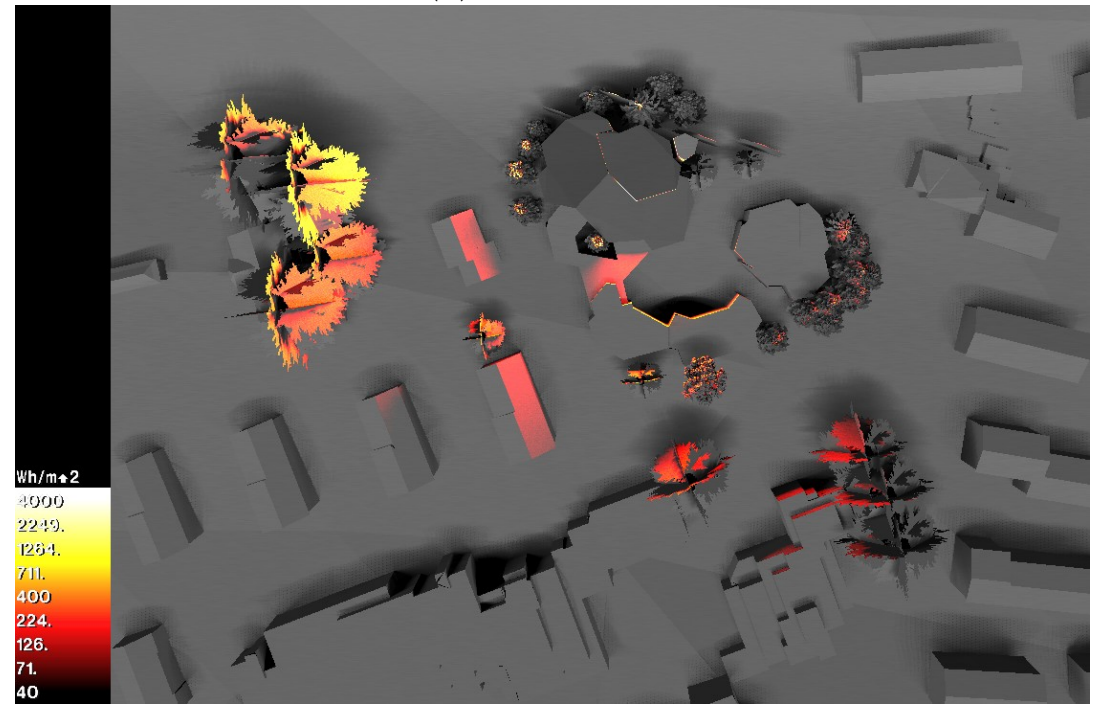

(c) Existing roof

Figure 10. Plan views of absolute cumulative annual irradiance in $\mathrm{Wh} / \mathrm{m}^{2}$ from standard $\mathrm{PV}(\mathbf{a})$, satinated PV (b) and existing roof tile (c). 


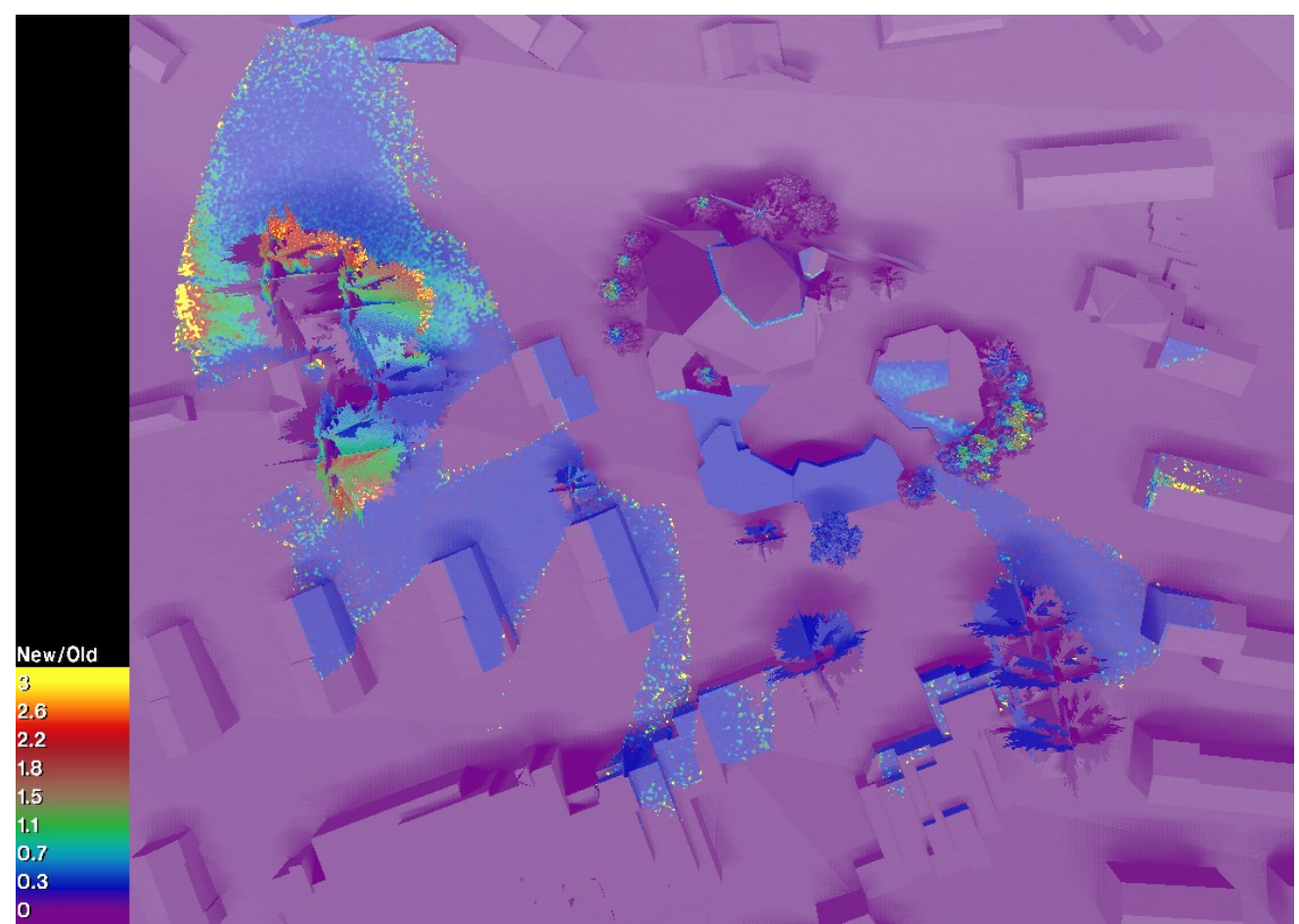

(a) Standard PV ("new") vs. existing roof ("old")

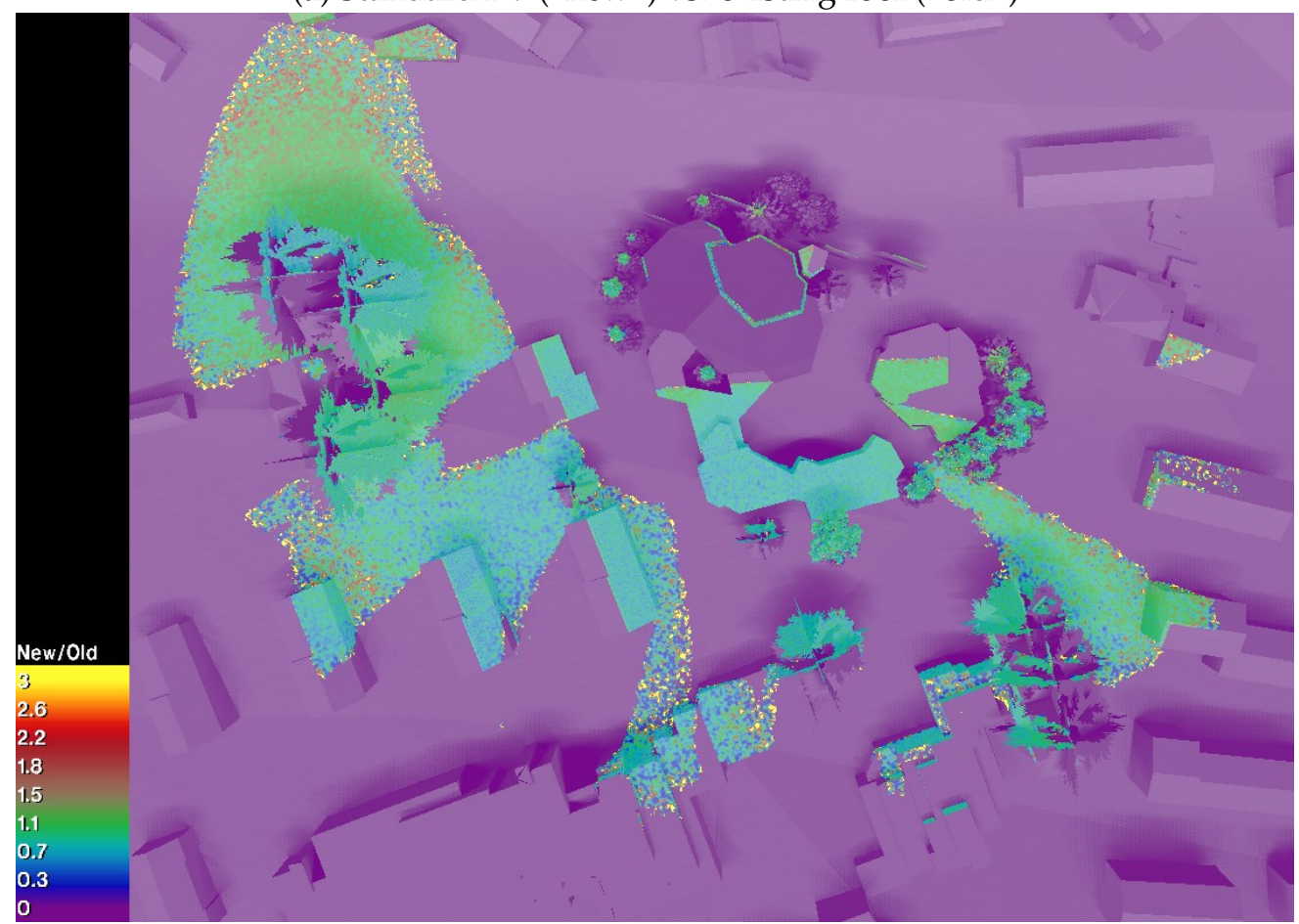

(b) Satinated PV ("new") vs. existing roof (“old")

Figure 11. Plan views of reflection distribution from standard (a) and satinated (b) PV in relation to the existing roof tile, expressed as irradiance ratios. 


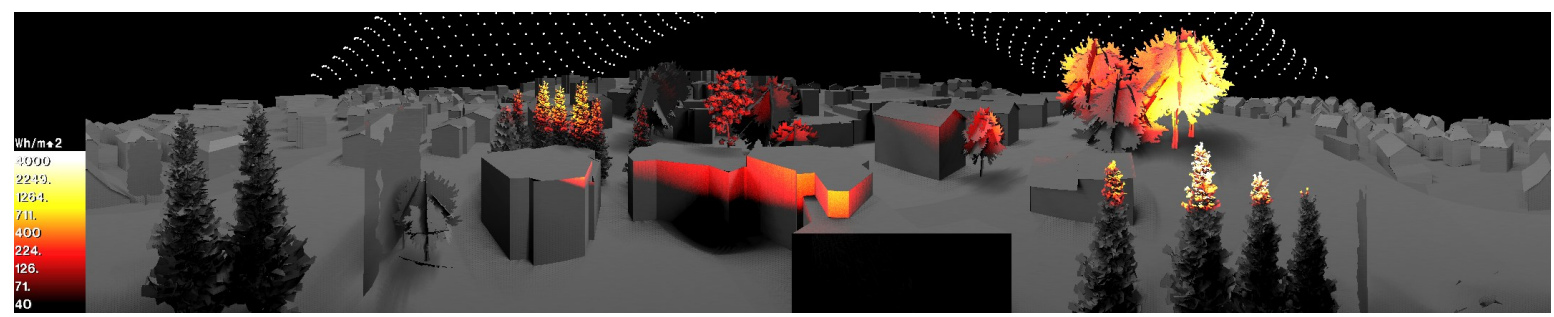

(a) Standard PV

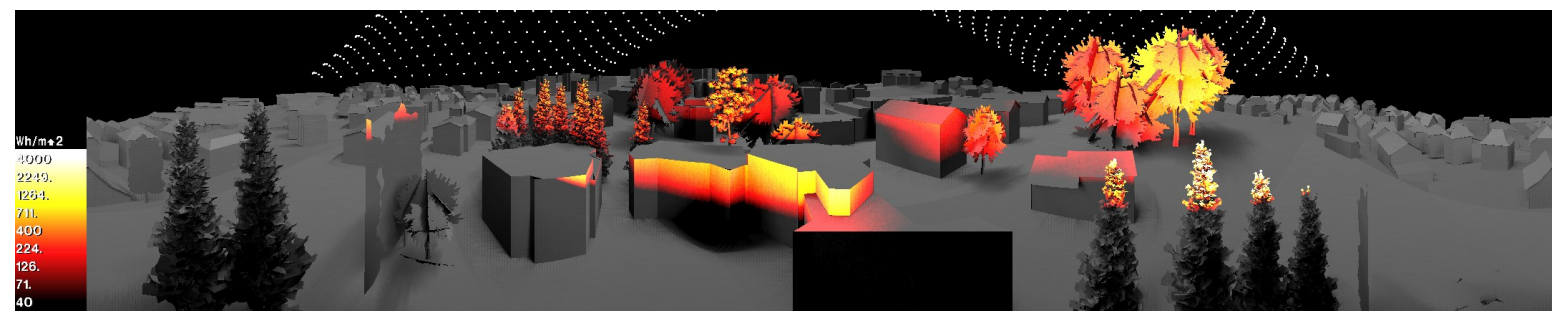

(b) Satinated PV

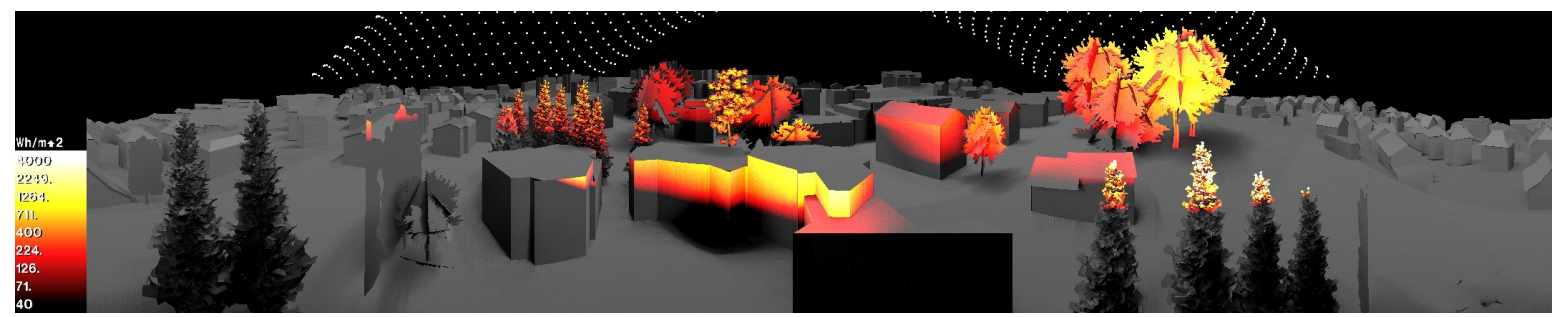

(c) Existing roof

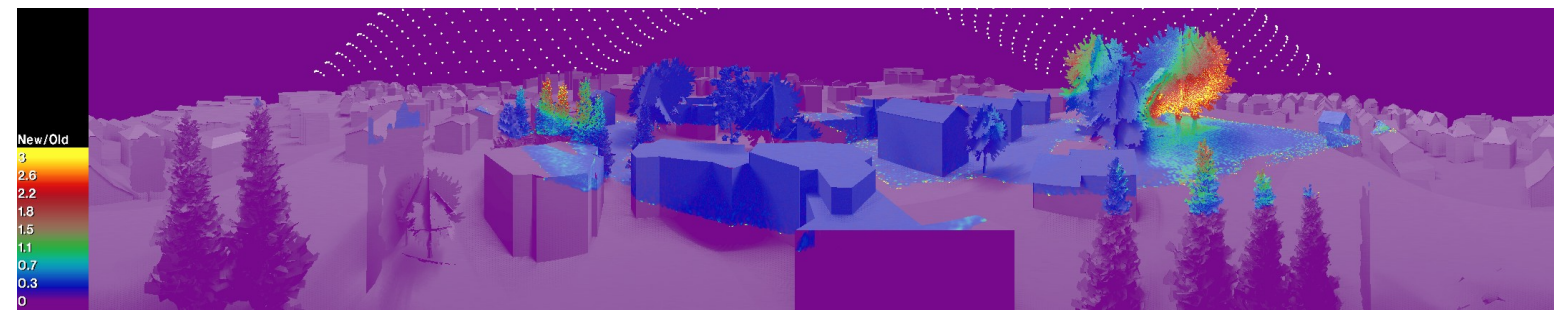

(d) Standard PV ("new") vs. existing roof ("old")

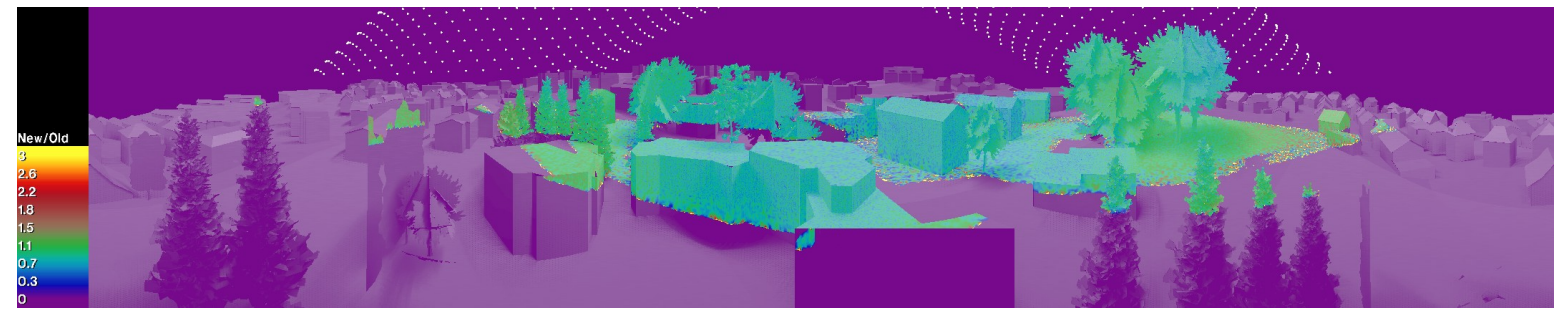

(e) Satinated PV ("new") vs. existing roof ("old")

Figure 12. Panoramic views of annual irradiance from standard PV (a,d), satinated PV (b,e) and existing roof tile (c), with centre facing south. $(\mathbf{a}-\mathbf{c})$ are in absolute units, while $(\mathbf{d}, \mathbf{e})$ are reflection distributions in relation to the existing roof tile, expressed as irradiance ratios.

The results of the proposed method agree well with the predictions for the first PV roof retrofit proposal in Figure 3. This is evident by superimposing a simulated plan view from Figure 10 obtained with the proposed method. The resulting composite, shown in Figure 13, confirms the initial prediction in terms of the locations and approximate timespans of the hotspots. The aforementioned hotspot on the group of trees in the west, predicted on summer mornings before ca. 8:30 a.m., matches well. Please note that while this initially predicted reflection zone extends towards the northwest, there are no buildings in this direction within the maximum distance $\tau_{d}$ of $100 \mathrm{~m}$ considered in the simulation. A secondary hotspot on the edge of the trees in the west-southwest on midsummer mornings before 
ca. 6:30 a.m. also matches. Lastly, minor hotspots on the treetops immediately adjoining the complex in the east-southeast on midsummer evenings after ca. 6:30 p.m. also correspond well.

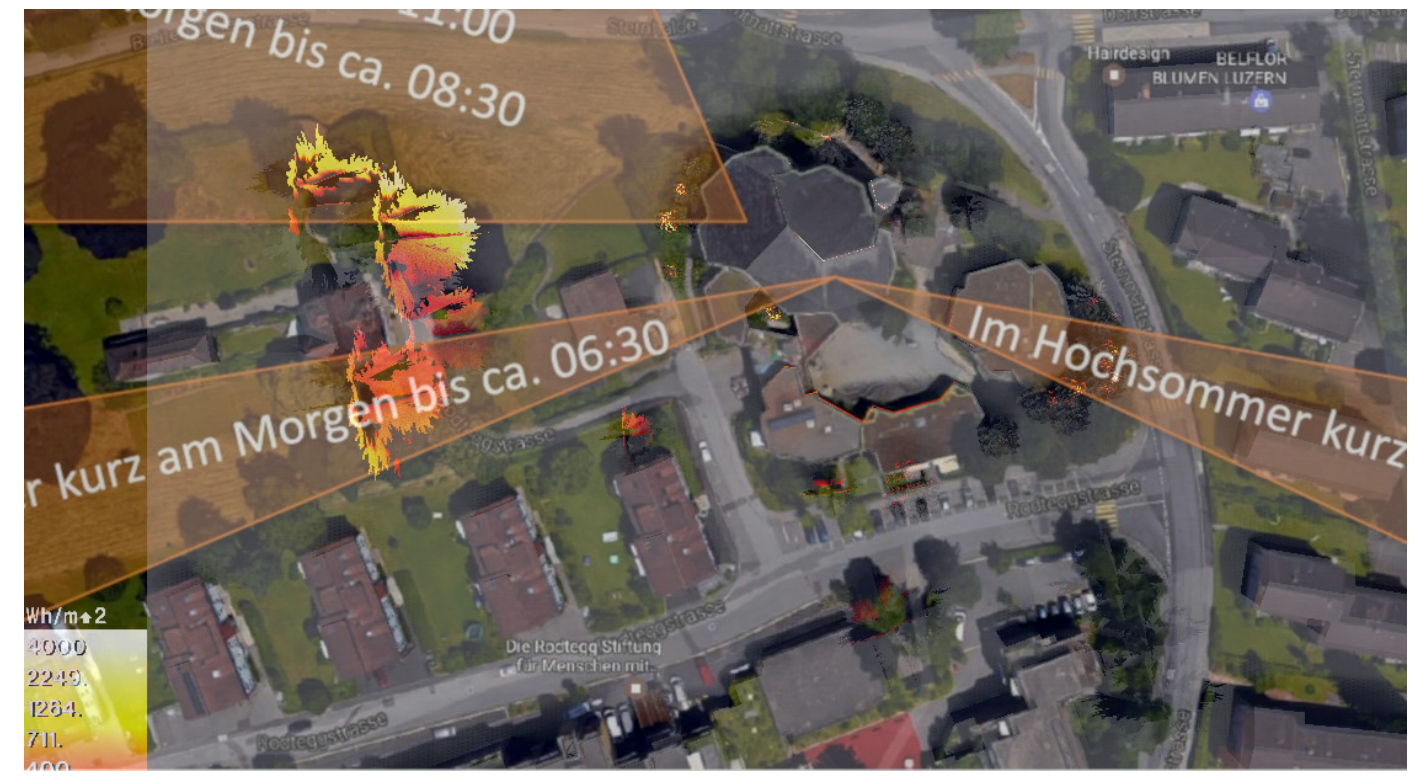

Figure 13. Reflection zones initially predicted by PV system installer (Figure 3) superimposed with plan view of simulated annual reflected irradiance obtained with the proposed method (Figure 10).

\subsection{Application of Recommended Criteria, Glare Duration}

An assessment of the potential for glare from the aforementioned hotspot is obtained by applying one of the recommended irradiance thresholds $\tau_{E}$ from Table 2 to the time-series irradiance maps in the spatio-temporal workflow. Figure 14 shows panoramic views of the cumulative annual glare duration obtained with a $\tau_{E}$ of $30 \mathrm{~W} / \mathrm{m}^{2}$ and $10 \mathrm{~W} / \mathrm{m}^{2}$ as recommended by Swissolar and Sandia Labs, respectively. Figure 15 shows the maximum sustained glare duration for any day of the year, i.e., per-pixel glare duration maxima for all simulated days. Again, this is shown as panoramic views for a $\tau_{E}$ of $30 \mathrm{~W} / \mathrm{m}^{2}$ and $10 \mathrm{~W} / \mathrm{m}^{2}$.

These visualisations provide a tangible prediction of likely glare according to the criteria. By condensing the temporal dimension into a single image quantifying the glare duration, and by isolating problematic zones, the visualisation is intuitive to PV planners, but more importantly, their clients and municipal planning authorities who will review the results. Radiometric units (which may be misinterpreted by non-experts) are replaced with the common unit of time, making this visualisation highly accessible.

With $\tau_{E}=30 \mathrm{~W} / \mathrm{m}^{2}$, there is no annual glare whatsoever from either candidate $\mathrm{PV}$, as shown in Figures 14 and 15. In stark contrast, applying Sandia Labs' more conservative threshold $\tau_{E}=10 \mathrm{~W} / \mathrm{m}^{2}$ indicates significant annual glare durations of up to $100 \mathrm{~h}$ in the group of trees to the west with the standard PV module. This is twice the maximum annual duration $\tau_{T}$ of $50 \mathrm{~h}$ recommended in Table 2 . As Figure 15 reveals for the same $\tau_{E}$, this region experiences a maximum sustained glare duration of up to 1 hour; again, twice the maximum glare duration $\tau_{t}$ of $30 \mathrm{~min}$ for any day of the year as recommended in Table 2. These glare incidents would be considered problematic were they to lie on adjacent buildings, warranting a luminance-based assessment from the corresponding observation point. In the context of this case study, however, it is assumed vegetation is impervious to glare, and will not take any recourse.

Both candidate PV materials are therefore considered viable for the retrofit and not critical in terms of glare. Subject to the constraints of the heritage protection board, the decision will likely be based on which candidate better preserves the existing appearance of the roof, with the satinated PV clearly being the favourable choice. 


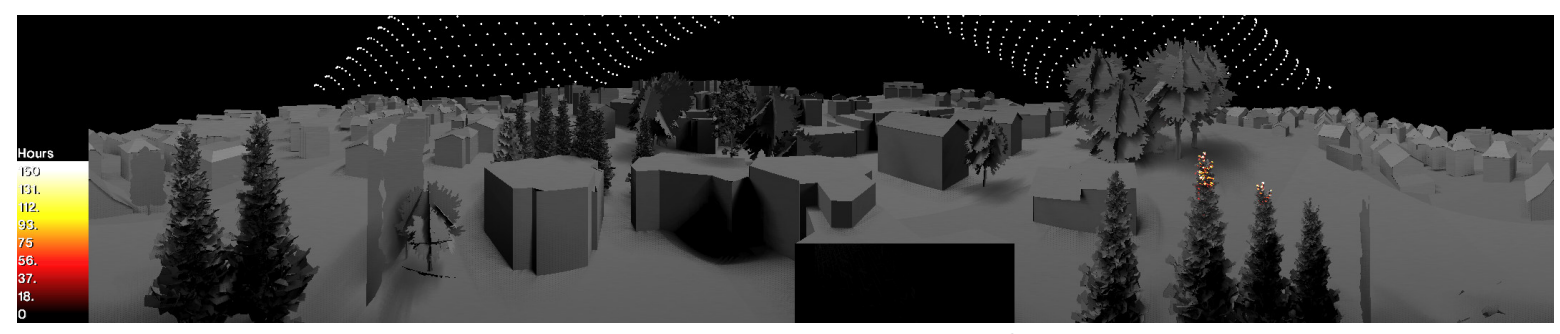

(a) Standard PV, $\tau_{E}=30 \mathrm{~W} / \mathrm{m}^{2}$

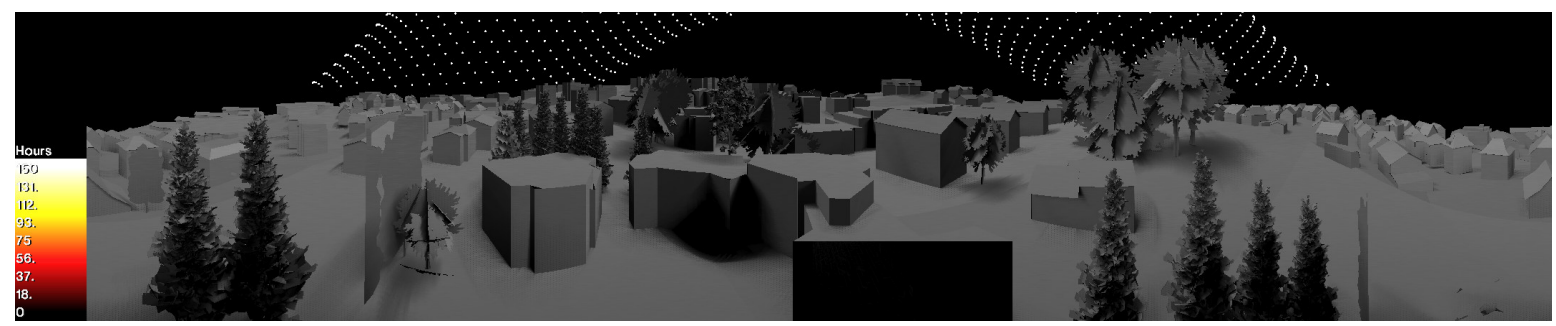

(b) Satinated PV, $\tau_{E}=30 \mathrm{~W} / \mathrm{m}^{2}$

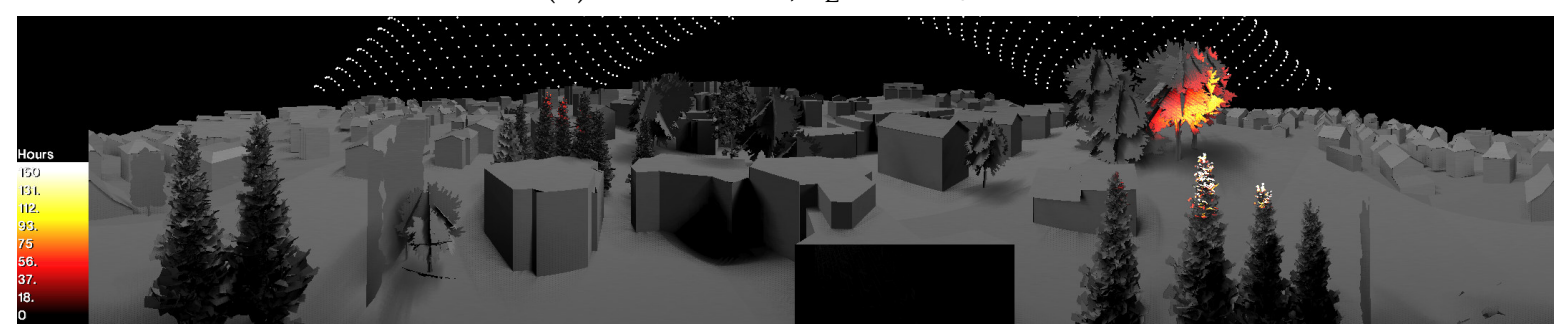

(c) Standard PV, $\tau_{E}=10 \mathrm{~W} / \mathrm{m}^{2}$

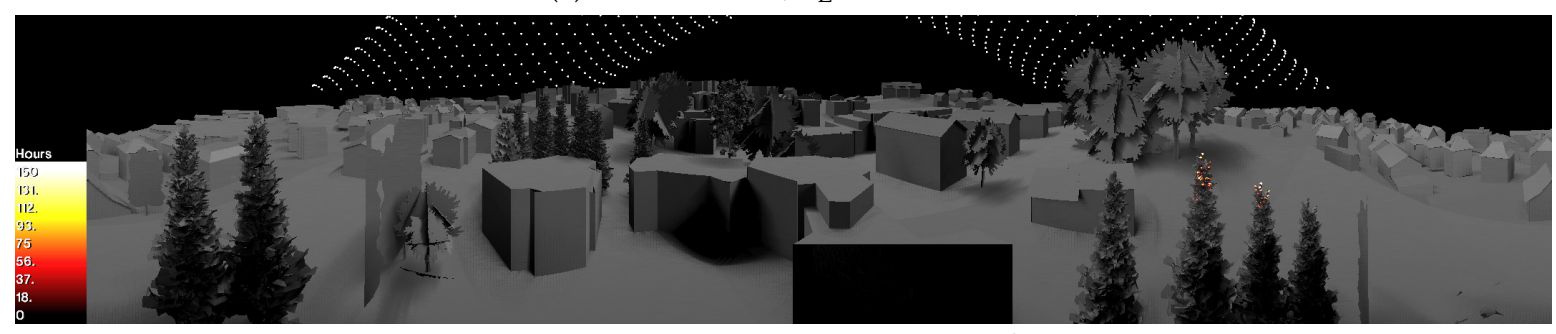

(d) Satinated PV, $\tau_{E}=10 \mathrm{~W} / \mathrm{m}^{2}$

Figure 14. Panoramic views of cumulative annual glare duration in hours for standard $(\mathbf{a}, \mathbf{c})$ and satinated (b,d) PV modules. Glare is identified according to irradiance thresholds $\tau_{E}=30 \mathrm{~W} / \mathrm{m}^{2}$ as recommended by Swissolar $(\mathbf{a}, \mathbf{b})$, and $\tau_{E}=10 \mathrm{~W} / \mathrm{m}^{2}$ as suggested by Sandia Labs $(\mathbf{c}, \mathbf{d})$. 


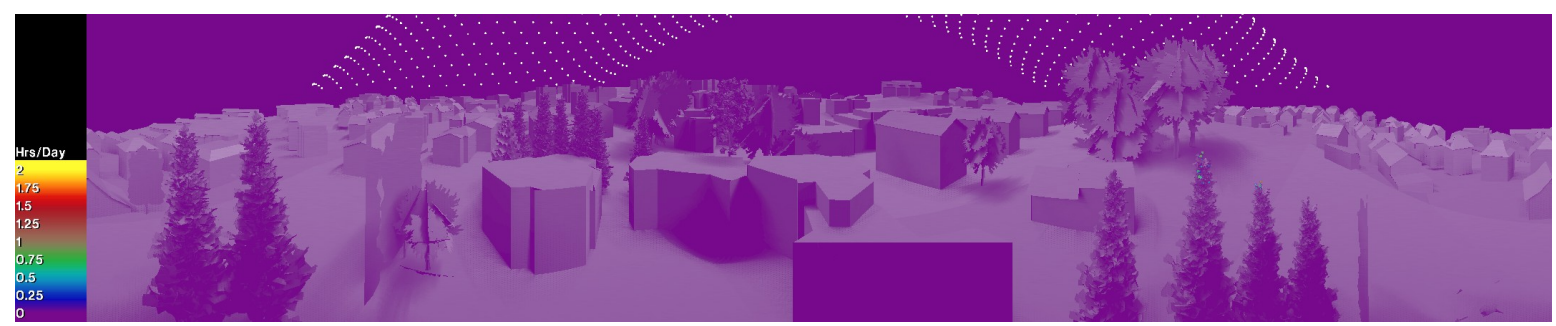

(a) Standard PV, $\tau_{E}=30 \mathrm{~W} / \mathrm{m}^{2}$

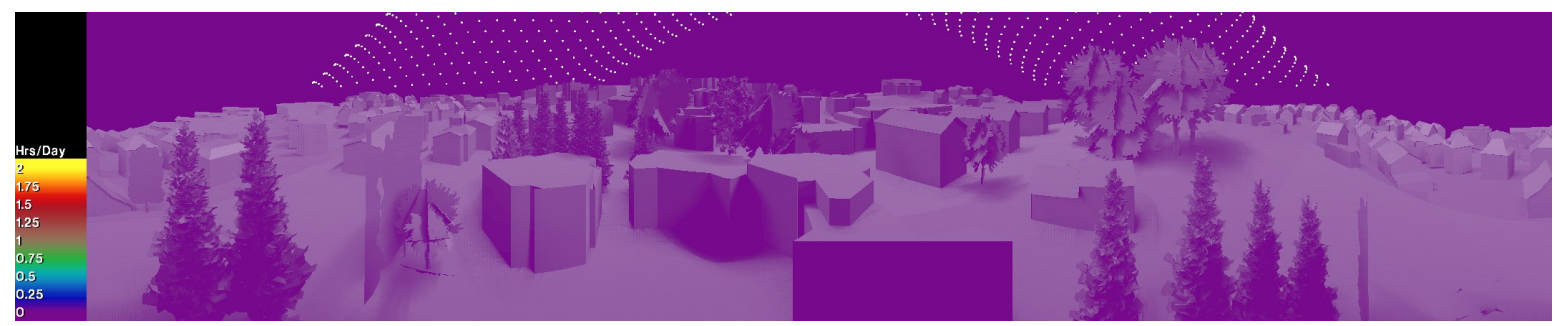

(b) Satinated PV, $\tau_{E}=30 \mathrm{~W} / \mathrm{m}^{2}$

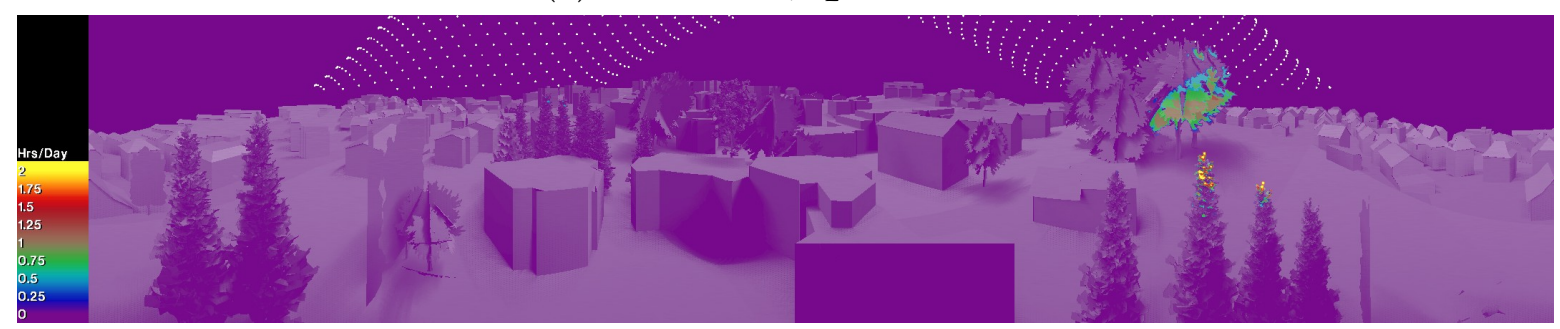

(c) Standard PV, $\tau_{E}=10 \mathrm{~W} / \mathrm{m}^{2}$

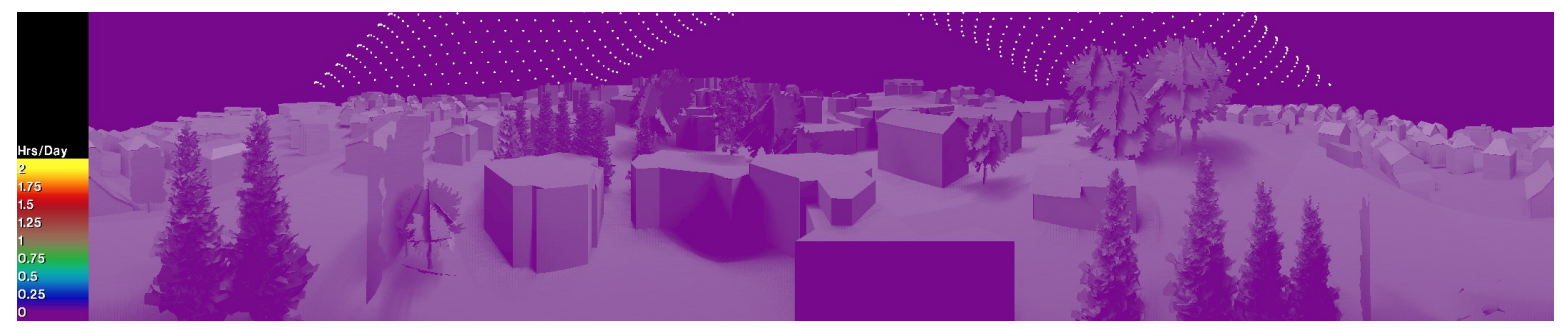

(d) Satinated PV, $\tau_{E}=10 \mathrm{~W} / \mathrm{m}^{2}$

Figure 15. Panoramic views of maximum sustained glare duration in hours for any day of the year incurred by reflections from standard $(\mathbf{a}, \mathbf{c})$ and satinated $(\mathbf{b}, \mathbf{d}) \mathrm{PV}$ modules. Glare is identified according to irradiance thresholds $\tau_{E}=30 \mathrm{~W} / \mathrm{m}^{2}$ as recommended by Swissolar $(\mathbf{a}, \mathbf{b})$, and $\tau_{E}=10 \mathrm{~W} / \mathrm{m}^{2}$ as suggested by Sandia Labs (c,d).

\subsection{Practical Applications and Impact}

The proposed method is expected to find applications in the following contexts, possibly in the form of a consultation service:

- Assessing proposed PV installations for compliance with regulations by building authorities and urban planners.

- Developing low-glare PV module surfaces by PV manufacturers.

- Defining PV glare assessment criteria, thresholds, and technical guidelines by trade associations.

- Establishing urban regulations concerning PV installations by government agencies.

The primary impact is expected to be an increased awareness of the side-effects from PV installations in urban environments, which will become more prevalent in the future. It is hoped this will also spawn further research towards refining the existing assessment criteria. With the proposed tool, the current thresholds can be refined in relation to their perception (e.g., discomfort or disability 
glare) by drawing on documented cases for which measurements are available, and simulating these. This can yield criteria that better accommodate individual responses and tolerances to glare, as well as providing insight into how these translate to simulation results.

\subsection{Limitations}

It should be acknowledged that the proposed workflow, as currently implemented, is a proof of concept, and therefore limited in a number aspects. Among these are:

- While using irradiance as physical metric is convenient to indicate potential glare, it is an integral quantity; as such, it may underrepresent isolated incidents of high radiance/luminance from reflectors subtending very small solid angles within an observer's field of view. While the resulting glare can even be disabling, such events tend to be of short duration (corresponding to glint), and may not appreciably impact the sustained glare duration.

- The background luminance (and therefore contrast) is not considered.

- The simulation depends on the accuracy and timeliness of the digital terrain model; in particular, vegetation is assumed to be a static, effectively opaque barrier irrespective of season in the case study.

- The PV surface models are derived from new production samples, and do not take weathering or manufacturing tolerances into account.

- While a sunny sky assesses the worst-case scenario, a more realistic assessment would be obtained using a climate-based sky model that accounts for typical cloud cover on site.

- The temporal resolution is currently $15 \mathrm{~min}$, which may be insufficient in detecting high-frequency glare. While the timestep increments can be finer grained, this increases simulation and postprocessing times.

- Timestamp increments are fixed, thus the simulation also expends considerable computational effort on timestamps that contribute negligible irradiance, rather than sampling adaptively.

- The current workflow is static and non-interactive, since the simulation must complete before the results can be assessed.

Some of these issues are addressed as future work in the conclusions.

\section{Conclusions and Future Work}

This paper presented a novel image-based methodology for assessing glare from PV reflections. The proposed methodology contributes the following to the existing body of work:

- A general workflow to assess cumulative annual irradiance from PV reflection, both in absolute terms and in relation to a reference material in order to compare different candidate PV surface materials.

- A novel, image-based spatio-temporal workflow that applies recommended assessment criteria and thresholds to quantify the cumulative annual glare duration, and the maximum sustained glare duration for any day of the year.

- A PV reflection simulation using data-driven material models of measured BSDFs.

- A digital terrain model of the site providing the urban context of the simulation.

- Photon mapping to efficiently precompute only the reflected component from the PV on the surrounding buildings.

- A falsecolour visualisation of reflected irradiance in the context of the built environment suitable for practitioners, municipal planning authorities and clients of PV installations. Including a background image of the built environment enables identification of potentially affected buildings. Such a visualisation is readily accessible to non-experts as well as practitioners.

The proposed method was demonstrated with a representative case study of a PV roof retrofit on a heritage protected site. Two candidate PV modules, standard and satinated, were measured from 
physical samples and simulated as data-driven BSDFs. Glare was then assessed by applying two alternative irradiance thresholds, $\tau_{E}=30 \mathrm{~W} / \mathrm{m}^{2}$, as recommended by Swissolar, and $\tau_{E}=10 \mathrm{~W} / \mathrm{m}^{2}$, as recommended by Sandia Labs. The results of the case study lead to the following conclusions:

- While the satinated PV module exhibits a homogeneous reflection distribution and no potential for glare at all, the standard PV module concentrates its reflections towards the west of the site during summer mornings (see Figure 11).

- The proposed spatio-temporal workflow identifies glare in the west when applying the conservative irradiance threshold of $10 \mathrm{~W} / \mathrm{m}^{2}$, which translates into an annual glare duration of ca. $100 \mathrm{~h}$ (see Figure 14) and a maximum sustained glare duration of $1 \mathrm{~h}$ for any day of the year (see Figure 15). These exceed the recommended limits of $\tau_{T}=50 \mathrm{~h}$ and $\tau_{t}=30 \mathrm{~min}$, respectively.

- While the standard PV module is likely to cause glare according to Sandia Labs' threshold, the affected zone is not critical, since it is populated by vegetation shielding a residential building behind it. This is noticeable in the plan views (see Figures 10 and 11).

- In consideration of the noncritical nature of the identified glare with the standard PV module, both candidates are viable replacements for the current roof. Because the site is heritage protected however, the satinated PV is more suitable in preserving the current appearance of the roof (see Figure 9).

- A comparison with predictions made in an earlier proposal for a PV roof retrofit confirmed that the proposed method indeed complements and supports the expertise of a PV planner (see Figure 13).

It should be emphasised that applying the recommended criteria in the proposed workflow does not constitute their validation. Whether the predicted glare is actually perceived as disturbing is, as the criteria themselves, highly subjective. Note, however, that the irradiance threshold recommended by Swissolar is based on a theoretical maximum. By contrast, the lower limits proposed by Sandia Labs and MIT are based on experimental data. If in doubt, either of the latter may be preferable in order to accommodate a higher tolerance in individual perception and reduce the likelihood of glare.

The proposed methodology is still a proof of concept both in terms of technological realisation and visualisation of the results. To address this and the limitations summarised in Section 5.4, the following avenues are being considered as future work:

- Optimisation of the scripts comprising the spatio-temporal workflow, particularly the memory footprint of the sustained glare extraction, which currently limits it to iteratively processing daily timesteps as the matrices tend to be very large (several gigabytes).

- Improvements to the daylight simulation engine. Progressive photon mapping techniques with visual feedback, for example, would introduce a degree of interaction to the simulations by allowing a planner to identify and react to hotspots early, while the results are still being refined. Currently the simulation runs to completion before the results can be reviewed.

- On a more fundamental level, the light transport algorithm at the heart of the simulation engine should be modified to more efficiently sample adaptively in both the spatial andtemporal domains. The raytracing algorithms currently employed in RADIANCE do not account for the latter, and annual simulations always use large numbers of fixed timesteps, with few actually contributing significantly to the results (i.e., as detectable glare in the analysis).

- The proposed method should be applied to a more comprehensive suite of extant case studies and recommended criteria, with the goal of refining the latter in terms of how the predicted glare is actually perceived on site.

With this paper, the authors intend to draw attention to the growing problem of glare from BIPV, as well as glass façades in general, and hope that the proposed method presented herein will stimulate future research in this field. Though still a proof of concept, this work can, after some maturation, support trade associations in defining assessment criteria, government agencies in establishing urban 
regulations, and PV manufacturers in developing low-glare PV modules. Lastly, it could simply result in fewer angry neighbours.

Author Contributions: S.W. initiated this research, supported it with consultations, and wrote the abstract and case study description. R.S. developed the simulation software and workflow scripts, ran the simulations, processed the data, visualised the results, and wrote the relevant sections comprising the bulk of the paper. C.R. advised on the proposed criteria and requirements from a practitioner's perspective, wrote the introduction and background on current legislation, and provided feedback on the results. All authors reviewed the publication.

Funding: This research was supported by the Swiss National Science Foundation as part of the project ACTIVE INTERFACES - Holistic strategy to simplify standards, assessments and certifications for building integrated photovoltaics (\#153849). The application of our workflow to a case study was supported by the city of Lucerne as part of the project Projektunterstützung Photovoltaik-Anlagen in schützenswerter Umgebung der Stadt Luzern (\#628) submitted by BE Netz AG, Ebikon.

Acknowledgments: This was an interdisciplinary effort involving architects, physicists, and computer scientists. We would like to thank the following for their invaluable contributions: digital terrain model of St. Michael's church and its surroundings (C) GIS Kanton Luzern; our colleague Ran Xu for preparing the digital terrain and church model and exporting it as RADIANCE geometry; our colleague Marek Krehel for obtaining the existing rooftile and PV samples and measuring their BSDFs in our goniophotometer; our colleague Lars O. Grobe for preparing the data-driven BSDF models for RADIANCE; and the anonymous reviewers for their valuable feedback.

Conflicts of Interest: The authors declare no conflict of interest.

\section{References}

1. Danks, R.; Good, J.; Sinclair, R. Assessing reflected sunlight from building facades: A literature review and proposed criteria. Build. Environ. 2016, 103, 193-202. [CrossRef]

2. Jakubiec, J.A.; Reinhart, C.F. Assessing Disability Glare Potential of Reflections from New Construction: Case Study Analysis and Recommendations for the Future. Transp. Res. Rec. 2014, 2449, 114-122. [CrossRef]

3. Carlucci, S.; Causone, F.; Rosa, F.D.; Pagliano, L. A review of indices for assessing visual comfort with a view to their use in optimization processes to support building integrated design. Renew. Sustain. Energy Rev. 2015, 47, 1016-1033. [CrossRef]

4. Henley, J. From the Walkie Talkie to the Death Ray Hotel: Buildings Turn up the Heat. The Guardian. 3 September 2013. Available online: https:/ / www.theguardian.com/artanddesign/shortcuts/2013/sep/ 03/walkie-talkie-death-ray-buildings-heat (accessed on 12 July 2018).

5. Burbank, L. L.A.'s Disney Hall Shines-A Bit Too Brightly. National Public Radio Inc., 2005. Available online: https:/ / www.npr.org/templates/story/story.php?storyId=4541963 (accessed on 12 July 2018).

6. Hayward, M. Airport Controllers Complain of Solar Panels' Glare. New Hampshire Union Leader. 30 August 2012. Available online: http:/ / www.unionleader.com/article/20120830/NEWS02/708309966 (accessed on 12 July 2018).

7. Bohren, A. Blendung von Solaranlagen: Übersicht zur aktuellen Rechtslage. In Proceedings of the Symposium Thermische Solarenergie, Bad Staffelstein, Germany, 6-8 May 2015; OTTI: Bad Staffelstein, Germany, 2015. Available online: http://www.spf.ch/fileadmin/daten/publ/Bohren_Blendung.pdf (accessed on 12 July 2018).

8. 20min.ch. Solaranlage Darf Nachbarn Blenden. 20 Minuten, 7 March 2012. Available online: http://www. 20min.ch/schweiz/news/story/Solaranlage-darf-Nachbarn-blenden-20629849 (accessed on 12 July 2018).

9. Battaglia, G. Grauer Star Wegen Solarpanel. Blick, 15 May 2017. Available online: https: //www.blick.ch/news/schweiz/geblendet-von-nachbarin-marlis-lauffer-traut-sich-bei-schoenemwetter-kaum-noch-in-den-garten-grauer-star-wegen-solarpanel-id6663759.html (accessed on 12 July 2018).

10. Bundesversammlung der Schweizerischen Eidgenossenschaft. Bundesgesetz über die Raumplanung (Raumplanungsgesetz) RPG; SR 700, 2018. Available online: https://www.admin.ch/opc/de/classifiedcompilation/19790171/index.html (accessed on 6 March 2018).

11. Der Schweizerische Bundesrat. Raumplanungsverordnung RPV; SR700.1, 2016. Available online: https: //www.admin.ch/opc/de/classified-compilation/20000959/index.html (accessed on 6 March 2018). 
12. Reichenbach, A.; Baumann, J.; Hofmann, D.; Nötzli, J.; Vonlanthen, J.; Wyss-Käppeli, B. Vollzugshilfe Lichtemissionen. Technical Report P282-1581, Bundesamt für Umwelt BAFU, 2017. Available online: https:/ / www.bafu.admin.ch/bafu/de/home/themen/elektrosmog/fachinformationen/lichtemissionen-lichtverschmutzung-/ konsultation-vollzugshilfe-lichtemissionen.html (accessed on 28 March 2018).

13. LAI. Hinweise zur Messung, Beurteilung und Minderung von Lichtimmissionen. Technical Report, Bund/Länder-Arbeitsgemeinschaft für Immissionsschutz (LAI), Potsdam, Germany. 2015. Available online: https:/ / www.lai-immissionsschutz.de/documents/hinweise_1503575680.pdf (accessed on 26 January 2018).

14. Stickelberger, D.; Moll, C. Leitfaden Solaranlagen. Technical Report, Swissolar, Schweizerischer Fachverband für Sonnenenergie, Zürich, 2017. Available online: http://www.swissolar.ch/fileadmin/user_upload/ Shop/170707_Leitfaden_RPG_Langfassung.pdf (accessed on 26 January 2018).

15. Ho, C.K.; Ghanbari, C.M.; Diver, R.B. Hazard Analyses of Glint and Glare from Concentrating Solar Power Plants. In Proceedings of the SolarPACES; AIP: Berlin, Germany, 2009. Available online: https:/ / www.semanticscholar.org/paper/Hazard-Analyses-of-Glint-and-Glare-from-Solar-Power-HoGhanbari/dcf8c285917f8b46cff00b0be425481c767deb57 (accessed on 27 March 2018).

16. Larson, G.W.; Shakespeare, R. Rendering With Radiance: The Art And Science of Lighting Visualization; Booksurge LLC: Charleston, SC, USA, 2004.

17. Rose, T.; Wollert, A. The dark side of photovoltaic-3D simulation of glare assessing risk and discomfort. Environ. Impact Assess. Rev. 2015, 52, 24-30. [CrossRef]

18. Sandia National Laboratories. Solar Glare Hazard Analysis Tool (SGHAT). 2017. Available online: https: / / share.sandia.gov/phlux (accessed on 27 March 2018).

19. Sims Industries. GlareGauge-Comprehensive Solar Glare Analysis. 2018. Available online: https://www. forgesolar.com/tools/glaregauge/ (accessed on 27 March 2018).

20. Yang, X.; Grobe, L.; Wittkopf, S. Simulation of Reflected Daylight from Building Envelopes. Proceedings Building Simulation 2013; IBPSA: Chambeéry, France. 2013. Available online: http://www.ibpsa.org/ proceedings/BS2013/p_1232.pdf (accessed on 6 March 2018).

21. Schregle, R. Development and Integration of the RADIANCE Photon Map Extension. Technical Report, Lucerne University of Applied Sciences and Arts. 2015. Available online: https:/ /www.researchgate.net/publication/ 272497518_Development_and_Integration_of_the_RADIANCE_Photon_Map_Extension_v112 (accessed on 27 March 2018).

22. Kunz, G. Kirchen in Luzern; Baukultur Entdecken; Innerschweizer Heimatschutz (IHS): Luzern, Switzerland, 2009.

23. Kanton Luzern. Geodaten-Portal. 2018. Available online: https://geoportal.lu.ch/geodaten (accessed on 16 May 2018).

24. Grobe, L.O.; Wittkopf, S.; Kazanasmaz, Z.T. High-resolution data-driven models of Daylight Redirection Components. J. Façade Des. Eng. 2017, 5, 101-113. [CrossRef]

25. Ward, G.; Kurt, M.; Bonneel, N. Reducing Anisotropic BSDF Measurement to Common Practice. In Proceedings of the Eurographics 2014 Workshop on Material Appearance Modeling: Issues and Acquisition (MAM '14), Lyon, France, 25 June 2014; Eurographics Association: Aire-la-Ville, Switzerland, pp. 5-8. Available online: http:/ / dl.acm.org/ citation.cfm?id=2855560.2855562 (accessed on 27 March 2018).

26. Schregle, R.; Grobe, L.; Wittkopf, S. An out-of-core photon mapping approach to daylight coefficients. J. Build. Perform. Simul. 2016, 9, 620-632. [CrossRef]

27. Schregle, R. The RAdiAnCE Photon Map Manual. 2016. Available online: https:/ /www.researchgate.net/ publication/303406111_The_RADIANCE_Photon_Map_Manual (accessed on 16 May 2018).

28. Jones, E.; Oliphant, T.; Peterson, P. SciPy: Open Source Scientific Tools for Python. 2001. Available online: http:/ / www.scipy.org/ (accessed on 14 May 2018).

(C) 2018 by the authors. Licensee MDPI, Basel, Switzerland. This article is an open access article distributed under the terms and conditions of the Creative Commons Attribution (CC BY) license (http:/ / creativecommons.org/licenses/by/4.0/). 